ఠ

\title{
Recent advances in the management of chronic
} stable angina I: Approach to the patient, diagnosis, pathophysiology, risk stratification, and gender disparities

\author{
This article was published in the following Dove Press journal: \\ Vascular Health and Risk Management \\ 14 July 2010 \\ Number of times this article has been viewed
}

\section{Richard Kones \\ The Cardiometabolic Research Institute, Houston, Texas 77054 USA}

Correspondence: Richard Kones, MD Cardiometabolic Research Institute, 8I8I Fannin Street, \#314, Houston, TX 77055 USA

Tel +17137909100

$\mathrm{Fax}+\mathrm{I} 7137909292$

Email drrkones@comcast.net

\begin{abstract}
The potential importance of both prevention and personal responsibility in controlling heart disease, the leading cause of death in the USA and elsewhere, has attracted renewed attention. Coronary artery disease is preventable, using relatively simple and inexpensive lifestyle changes. The inexorable rise in the prevalence of obesity, diabetes, dyslipidemia, and hypertension, often in the risk cluster known as the metabolic syndrome, drives the ever-increasing incidence of heart disease. Population-wide improvements in personal health habits appear to be a fundamental, evidence based public health measure, yet numerous barriers prevent implementation. A common symptom in patients with coronary artery disease, classical angina refers to the typical chest pressure or discomfort that results when myocardial oxygen demand rises and coronary blood flow is reduced by fixed, atherosclerotic, obstructive lesions. Different forms of angina and diagnosis, with a short description of the significance of pain and silent ischemia, are discussed in this review. The well accepted concept of myocardial oxygen imbalance in the genesis of angina is presented with new data about clinical pathology of stable angina and acute coronary syndromes. The roles of stress electrocardiography and stress myocardial perfusion scintigraphic imaging are reviewed, along with the information these tests provide about risk and prognosis. Finally, the current status of gender disparities in heart disease is summarized. Enhanced risk stratification and identification of patients in whom procedures will meaningfully change management is an ongoing quest. Current guidelines emphasize efficient triage of patients with suspected coronary artery disease. Many experts believe the predictive value of current decision protocols for coronary artery disease still needs improvement in order to optimize outcomes, yet avoid unnecessary coronary angiograms and radiation exposure. Coronary angiography remains the gold standard in the diagnosis of coronary artery obstructive disease. Part II of this two part series will address anti-ischemic therapies, new agents, cardiovascular risk reduction, options to treat refractory angina, and revascularization.
\end{abstract}

Keywords: angina, coronary artery disease, ischemic heart disease, myocardial oxygen balance, cardiovascular risk assessment, acute coronary syndrome, electrocardiographic stress testing, stress myocardial perfusion imaging, gender disparities in heart disease, silent ischemia, coronary angiography

\section{Introduction}

Atherosclerosis and its consequences: coronary artery disease, stroke, peripheral artery disease, and aortic and renal arterial disease are modern plagues of civilization. However, it should give us pause to learn that atherosclerotic lesions have been identified in 3500-year-old Egyptian mummies, ${ }^{1}$ with mention of chest pain syndromes in 
hieroglyphics of papyruses, although certainly this was a negligible health concern at that time. Fast forwarding to this century, cardiovascular disease is now the most common cause of death, and evidence is now overwhelming that our diets and lifestyle are chief causes of obesity, diabetes, dyslipidemia and inflammation leading to atherosclerosis. The role of inflammation in etiology and as a potential therapeutic target is a topic of intense ongoing interest. ${ }^{2-8}$

Considerable data show that atherosclerosis and coronary artery disease (CAD) are preventable diseases. The data further indicate that population-wide dietary changes that include a plant-based, calorie controlled intake of fresh, whole foods low in sodium and sugar, avoidance of saturated and trans fats, together with a higher consumption of omega-3 fatty acids and perhaps olive oil, combined with adequate physical activity, could substantially eliminate the disease. ${ }^{9,10}$ Public health implications are compelling, but proven lifestyle recommendations remain unheeded. ${ }^{11,12}$

According to the latest American Heart Association (AHA) Statistics $2010,{ }^{11}$ overall prevalence of angina is $4.6 \%$ in the USA, affecting 10,200,000 persons, compared with a total number of 17,600,000 patients with CAD. Angina therefore afflicts 58\% of patients with CAD. ${ }^{11}$ Approximately 500,000 new cases are reported yearly, and prevalence rises rapidly with increasing age. While anginal attacks are considered reversible short term, they are by no means benign, with significant morbidity and mortality. ${ }^{13,14}$ New-onset angina, defined as beginning within 2-3 months prior to presentation, has a poor prognosis, ${ }^{13,15}$ with about $10 \%$ of patients experiencing a nonfatal myocardial infarction or coronary death during the next year. ${ }^{16}$ While much of the data has been collected in men, it is now recognized that in women too, angina is not benign, with a $19 \%$ mortality rate within 4.5 years. ${ }^{17}$

The expense involved in controlling angina is considerable, approaching $\$ 1.1$ million per capita as a lifetime cost in 2006 dollars for women. ${ }^{18}$ The estimated total direct and indirect cost of CAD for 2010 in the United States is about $\$ 177.1$ billion. In weighing statistics, it should be emphasized that many millions of people with CAD remain undiagnosed, making the numbers, as striking as they are, actually conservative.

\section{Definition}

Angina, herein referring to angina pectoris, derives from the Latin angore, meaning choking and suffocation, but also anxiety, fear, or terror. Angina was recognized in the Middle Ages, but the description in 1768 by William Heberden is far better known. ${ }^{19}$
Angina is chest discomfort caused by myocardial ischemia without necrosis, and is further qualified by its precipitating factors, time course to relief, and clinical characteristics, such as radiation and quality. Typical angina may be triggered by increased activity (exercise, sex), emotional stress (anger, fright, stress), or cold, wind, and fever. The discomfort of exertional angina is relieved by rest within 1-5 min, or more rapidly with sublingual nitroglycerin. Episodes last from 2-10 min. Classically there is heaviness or pressure retrosternally, with possible radiation to the ulnar aspect of the left arm, neck, jaw, mid-abdomen, right arm or shoulders. The average frequency of anginal attacks in patients is about 2 per week. Many patients voluntarily curtail their activities to avoid attacks.

Clinically, angina may be further subdivided according to common usage, as follows:

\section{- Chronic, stable}

As described above, chronic stable angina is generally due to one or more significant obstructive lesions in coronary arteries, obstructive lesions defined as stenosis of $\geq 50 \%$ of the diameter of the left main coronary artery or stenosis of $\geq 70 \%$ of the diameter of a major epicardial vessel. Precipitating circumstances remain similar between episodes, thresholds may be predicted by patients, and relief patterns become known. Since stenoses are fixed, the angina is due to demand ischemia.

\section{- Decubitus}

Attacks of decubitus angina occur upon recumbency, which raises end-diastolic volume, myocardial wall tension, and hence oxygen demand.

\section{- Nocturnal}

Anginal discomfort awakens the patient, generally due to respiratory pattern changes, episodic tachycardia, hypoxia due to respiratory changes, or recumbency.

\section{- Refractory}

Stable chronic angina is termed refractory when it is not controllable by a combination of maximal anti-anginal medication, angioplasty or coronary artery bypass surgery, or in whom the risks are unjustified.

\section{- Unstable (also called crescendo or rest)}

Unstable angina (UA), is

- of recent onset, and/or

- discomfort is severe, and/or

- occurs at rest or after minimal exertion lasting over $10 \mathrm{~min}$, and/or

- angina with a crescendo pattern - more frequent, more severe, of greater duration, or less responsive to nitroglycerin. 
UA is an acute coronary syndrome (ACS), and when myocardial necrosis becomes evident from elevations in biomarkers, such as troponin I and troponin $\mathrm{T},{ }^{20}$ the applicable clinical term becomes non-ST-elevation myocardial infarction, or NSTEMI, in the absence of ST-segment changes. The European Society of Cardiology defines ACS as acute chest pain (ie, chest pain at rest $>20$ min within the prior 48 hours) together with electrocardiographic (ECG), changes suggesting myocardial ischemia and/or elevation of cardiac markers. ${ }^{21}$ About 1.35 million patients are admitted to US hospitals annually with the diagnosis of unstable angina-NSTEMI. From 38\%-47\% of patients with ACS have ST-segment elevations on the ECG, known by the acronym STEMI.

\section{- Microvascular (also called Syndrome X)}

More common in women, angina-like pain, normal coronary angiograms, and positive exercise tests, sometimes with perfusion defects, are a basic diagnostic triad in microvascular angina. ${ }^{22}$ Response to nitrates and other anti-ischemic agents is less reliable, and hormonal abnormalities, changes in pain perception with exaggerated sensitivity, insulin resistance, and psychological overlays may be modifying factors. Endothelial dysfunction is one pathophysiological suspect, ${ }^{23}$ but release of vasoactive substances, autonomic dysfunction, vascular smooth muscle dysfunction and loss of estrogen may all contribute. Chest pain may occur under conditions of cardiac stress without evidence of ischemia. GERD and esophageal motility disorders are common comorbidities. In part, treatment is difficult because therapeutic responses are not sustained. About $1 \%$ of patients die and $0.6 \%$ suffer a stroke within one year after their first hospital admission.

- Vasospastic (also called Prinzmetal's, or angina inversa) $)^{24,25}$

Described in 1959, this variant form of angina occurs at rest, often at night, or with exertion, is caused by focal vasospasm of an epicardial coronary artery, and is not due to obstructive atherosclerotic lesions. Prinzmetal's angina is known for transient elevation, rather than depression, in ST-segments on the electrocardiogram, although either may occur. However, most acute patients with coronary vasopasm do not have ST-segment elevations, which are identified more often during an attack or upon provocative testing. Despite an increase in ventricular arrhythmias in some patients, the prognosis is generally better than those with fixed, significant obstructive lesions, although response to treatment may be poor. ${ }^{26}$ In the CASPAR study, every fourth patient with an ACS had no culprit lesion at coronary angiography, and in those patients epicardial coronary spasm could be documented in $50 \% .{ }^{27}$ Coronary vasospasm is a more common cause of chest pain and ACS than formerly believed, and may contribute to pathology with or without coexisting obstructive plaques, more frequently found in men. ${ }^{28}$ Over the years, vasospasm has been linked to low intracellular magnesium levels, hyperinsulinemia, defective focal nitric oxide production, and use of tobacco or cocaine.

\section{- Atypical angina}

Patients with nonclassical symptoms and signs, such as absence of substernal location and character, exertional trigger, or typical relief with rest or nitroglycerin, are grouped under the term atypical angina. Atypical presentations are more frequent in women and diabetics, displaying variable pain intensity or thresholds, timing, and characteristics. Palpitations, sharp lancinating or back pain are confounding complaints. The more atypical the presentation, results of testing, and responses to provocation or therapy, the greater the probability of misdiagnosis and a poor outcome (see below).

\section{- Silent ischemia and anginal equivalents}

In some patients, particularly diabetics and the elderly, ${ }^{29}$ myocardial ischemia may cause symptoms other than precordial discomfort. These may include dyspnea, diaphoresis, nausea and emesis, fatigue, weakness, altered sensorium, light headedness, and fainting. In the absence of chest pressure, heaviness, pain or sensorial cognition, ischemia is also called silent. Altered pain perception and presence of autonomic neuropathy may modulate symptom expression. Patients with silent ischemia are less likely to be diagnosed correctly and receive appropriate attention and treatment, resulting in poorer outcomes. In fact, even if there are clear objective findings, such as subsequent ST-segment elevation, the absence of chest pain during the initial presentation still decreases utilization of both fibrinolysis and percutaneous coronary intervention (PCI) later on in such patients' treatment. ${ }^{30}$

\section{Diagnosis}

Although about $25 \%$ of people experience chest pain, ${ }^{31} 77 \%$ of them do not seek medical care despite widespread public educational efforts. ${ }^{30}$ The number of patients presenting with chest pain eventually found to have $\mathrm{CAD}$ ranges from 11 to $39 \%,{ }^{23}$ but reports trend closer to $12 \%{ }^{23}$ Of those seen in emergency rooms, about $45 \%-50 \%$ will have a cardiac etiology, ${ }^{30,32}$ with the remaining 50\%-55\% diagnosed with noncardiac chest pain. ${ }^{31}$ In primary care practices, 
however, the most common conditions encountered are gastroesophageal reflux disease (GERD), musculoskeletal pathology, other gastrointestinal conditions, panic disorder, pulmonary disease, and stable chronic angina. ${ }^{33,34}$ Ischemic pain is often neglected by patients who mistakenly attribute the pain to an episode of indigestion or gas. Characteristically this history is elicited retrospectively after it is clear the patient has ischemic heart disease.

Questions to ask about chest pain include: ${ }^{35}$

1. Background, character, and development of the symptoms. For instance, whether pain occurred during effort, an acute febrile illness, after trauma.

2. Area involved, with radiation, if any.

For instance, requesting that the patient point to the area of pain with a finger may help with focus and elicit a response of a clenched fist.

3. Triggers that initiate the pain.

For instance, whether pain occurred during effort, emotional stress, sports events on TV, position, eating, etc. The threshold of pain may be lower after smoking, eating, or cold weather.

4. Frequency, progression, and duration of the pain.

5. Factors that relieve the pain.

For instance, variation of pain with rest, maneuvers, position, eating, eructation, antacids, proton pump inhibitors, nitroglycerin.

The precipitating factors, characteristics, and natural course of angina, along with antecedent history, are typically of greater value in evaluation than the physical examination, which is normal in most patients. Discomfort is usually described as heaviness, tightness, crushing, squeezing or pressure in the precordial, substernal or even epigastric area, much more common than peripheral radiation, with or without numbness. It is said that radiation to the arms, diaphoresis and hypotension suggests myocardial infarction. Angina does not vary with change in position, the respiratory cycle or cough. Angina reported postprandially is not usually of differential diagnostic value. Angina or any equivalent, including absence of pain during silent ischemia, may be accompanied by dyspnea, nausea, diaphoresis, weakness/ fatigue and apprehension. Therefore, any patient of appropriate age with naked, unexplained weakness, dyspnea, or nausea, particularly precipitated by activity, sex, or emotion, should be investigated for ischemic heart disease along with other usual possible etiologies.

Angina must be differentiated from other causes of chest pain, the most common summarized in Table 1.

\section{Production and significance of pain}

Myocardial ischemia stimulates cardiac sensory receptors to initiate a sympathoexcitatory reflex. Bradykinin, protons, and other substances released during ischemia activate the vallinoid receptor 1 (VR-1) on capsaicin-sensitive cardiac sensory nerves (unmyelinated [type C] or thinly myelinated $[\mathrm{A}-\delta]$ fibers).$^{37}$ The VR-1 receptor acts as a transducer responsible for sensing tissue ischemia, and through sympathetic activation, leads to the sympathoexcitatory reflex and the pain of angina. ${ }^{38}$

Table I Some noncoronary causes of chest pain

\begin{tabular}{|c|c|}
\hline System & Diagnoses \\
\hline Gastrointestinal & $\begin{array}{l}\text { Peptic ulcer, gastritis, GERD, cholecystitis, cholelithiasis, choledocholithiasis, esophageal spasm, } \\
\text { esophagitis, esophageal perforation, pancreatic diseases, some causes of "acute abdomen" such as } \\
\text { perforations, volvulus, mesenteric adenitis, etc. GERD accounts for up to } 60 \% \text { of noncardiac cases. }{ }^{36}\end{array}$ \\
\hline Musculoskeletal & $\begin{array}{l}\text { Chest wall trauma/rib fracture, costochondritis, muscle/ligament/tendon strains, myositis, chronic } \\
\text { overuse injuries, sternoclavicular arthritis }\end{array}$ \\
\hline Pulmonary & $\begin{array}{l}\text { Pulmonary embolism, severe pulmonary hypertension, pleuritis, pneumonia, pneumothorax, } \\
\text { bronchiectasis }\end{array}$ \\
\hline Nervous & Cervical radiculopathy, peripheral neuropathy, brachial plexus impingement, brachial neuritis \\
\hline Psychiatric & $\begin{array}{l}\text { Generalized anxiety disorder, panic disorder, hyperventilation, depression, somatoform disorders, } \\
\text { fixed delusions in thought disorders }\end{array}$ \\
\hline Other cardiovascular & $\begin{array}{l}\text { Pericarditis, acute aortic dissection, aortic stenosis, mitral valve prolapse, idiopathic hypertrophic } \\
\text { subaortic stenosis (IHSS), cardiac contusion, acute stress cardiomyopathy (Takotsubo's disease), } \\
\text { uncontrolled hypertension, coronary anomalies, Kawasaki disease (mucocutaneous lymph node } \\
\text { syndrome), polyarteritis nodosa, Takayasu arteritis (aortic arch syndrome) }\end{array}$ \\
\hline Infectious & Herpes zoster prior to rash, acute lymphadenopathy, Pott's disease (tuberculous spondylitis) \\
\hline Metabolic & Hyperviscosity syndrome, acute thyrotoxicosis \\
\hline $\begin{array}{l}\text { Related processes that modulate } \\
\text { oxygen supply and demand }\end{array}$ & $\begin{array}{l}\text { Angina may be intensified or caused by hypotension, hypoxia, anemia, bradycardia, } \\
\text { fever, thyrotoxicosis, high output states, such as A-V shunts, systemic and inflammatory } \\
\text { diseases, especially sepsis, an example of demand ischemia. A hemoglobinopathy } \\
\text { or carbon monoxide poisoning may interfere with oxygen delivery. }\end{array}$ \\
\hline
\end{tabular}


Simultaneously, cardiac sensory nerves also release neuropeptides, among them calcitonin gene-related peptide, substance $\mathrm{P}$ (SP), and neurokinin A, believed to modulate myocardial ischemia/reperfusion injury. ${ }^{39}$ By dilating the coronary arteries and through their negative inotropic and chronotropic actions, they could reduce negative ischemic effects, in part mediated by raised amounts of nitric oxide produced by secondary actions of $\mathrm{SP}^{40}$ Considerable data now support an increasingly popular view that VR-1 receptors protect the heart during ischemia. ${ }^{41,42}$ Cardiac afferents from the first four thoracic spinal neurons, after interacting with other nerves and signals from descending supraspinal locations, ascend along spinothalamic afferents to the thalamus on their way to the cerebral cortex. Anxiety and/or stress, frequently associated with $\mathrm{CAD}$, upregulate glucocorticoid release and increase sensitization to cardiac nociceptive stimuli by modulating upper thoracic neuronal activity. ${ }^{43}$ Awareness of the pain may be variable, in part due to an interpretive component in the cortex.

It is possible that diabetics have more severe ischemia related to neuropathy because their VR1 sensitivity and SP production are impaired. Preclinical studies also suggest that a reduction in nerve growth factor in diabetics may account for failure to experience pain. ${ }^{44}$ Some evidence exists that central processing of afferent pain signals from the heart mediates lack of pain in patients with silent ischemia. Pain messages are, however, physically received by the brain in these patients.

In the light of this new information, angina appears to serve as a warning to the patient to stop activity that may further ischemic damage and obtain medical care, but simultaneously initiates some degree of myocardial protection.

\section{Silent ischemia}

Silent ischemia is angina without pain, a unique clinical challenge.

While angina is considered a common diagnosis in clinical practice, it is highly likely that prevalence rates remain underestimated. Asymptomatic and hence undiagnosed myocardial infarction accounted for $33 \%$ of transmural (Q-wave) myocardial infarctions identified by serial electrocardiographic changes and $22 \%$ of all nonfatal infarctions in the Honolulu Heart Program. ${ }^{45}$ Recently, using a delayed enhancement cardiac MRI (DE-CMR), which identified both Q-wave and non-Q-wave myocardial infarctions, a study was conducted in 502 subjects with extracardiac atherosclerotic disease or advanced risk factors for CAD but without symptoms. ${ }^{18}$ An unrecognized myocardial infarction was identified in $13.1 \%$ of men and $3.7 \%$ of women. There was also a suggestion that silent events were associated with a poorer prognosis. In the elderly, from $21 \%$ to $68 \%$ of all myocardial infarctions are asymptomatic or unrecognized as determined by electrocardiography. ${ }^{18,46,47}$ In high risk patients evaluated with dual-isotope myocardial perfusion SPECT, silent myocardial infarction is also common. ${ }^{48}$

Additionally, silent ischemia is surprisingly frequent during continuous electrocardiography, exercise testing, or stress echocardiography in high risk patients in a variety of clinical situations. Up to $75 \%$ of ischemic (ST-segment depression $\geq 1 \mathrm{~mm}$ for $\geq 1 \mathrm{~min}$ ) episodes may occur without pain. ${ }^{49}$ When clinical symptoms of stable angina are thought to be controlled, at least $40 \%$ of those patients continue to show ischemia on monitoring. ${ }^{50}$ The longer patients continue to be monitored, the greater the number of ischemic episodes that are detected. ${ }^{51}$

All things considered, it is becoming evident that most ischemic cardiac events are asymptomatic and unrecognized, even in patients with typical stable angina who consider themselves extremely aware. From $10 \%-20 \%$ of diabetics have silent ischemia and the burden is rising. From the significant number of silent myocardial infarctions found on electrocardiography and MRI, and asymptomatic ischemic episodes during exercise provocation or ambulatory STsegment monitoring, a great number of would-be anginal attacks also go unrecognized, undiagnosed, and undertreated. Hence the clinical reporting of anginal episodes is quite insensitive. Since continuous ECG monitoring is also underutilized, the clinical implications are immense.

Patients with silent ischemia have a poorer prognosis than those with classical symptoms and may require more aggressive therapy ${ }^{49,52,53}$ Just one or a few episodes of ST-segment depression on 24 hour continuous monitoring is associated with a 7.43 rise in risk of AMI or death at 30 days in patients with unstable angina. ${ }^{52,54}$ Silent ischemia remains a formidable unsolved clinical problem in all its guises, ${ }^{55-58}$ not only with respect to the absence of anginal pain. In medicine, random, instant, "snap-shot", or "ice-pick" samples of elements of disease, even as deceptively simple as blood pressure or serum glucose measurements, may be disastrously misleading when compared to continuous recordings.

\section{Classification and grading}

Symptom intensity does not necessarily reflect severity or extent of coronary obstruction, but assessment is helpful and included in current guidelines. ${ }^{59}$ Angina is classified with respect to functional capacity by the New York Heart 
Association functional classification, and according to severity by the Canadian Cardiovascular Society (Table 2).

The Canadian Cardiovascular Society classes correspond to the exercise tolerances, shown in Table 3, in metabolic equivalent units, MET: ${ }^{62,63}$

$\mathrm{MET}=$ metabolic equivalent of a task, relative to the nominal resting metabolic rate

$$
=3.5 \mathrm{~mL} \mathrm{O}_{2}\left(\mathrm{~kg}^{-1} \mathrm{~min}^{-1}\right)
$$

\section{Pathophysiology Myocardial energy (oxygen) balance}

For over 40 years, it has been recognized that myocardial ischemia results from an imbalance between myocardial energy supply, from insufficient sources of oxygen and substrate (glucose, free fatty acids), and myocardial oxygen demand. ${ }^{64-67}$ Usually this is simply referred to as an imbalance between myocardial oxygen supply and demand, but it should be clear that substrate supply, utilization, and enzymatic activities, along with other variables involved in intermediary metabolism and mitochondrial function, play a major role in the pathogenesis of myocardial ischemia in angina, acute coronary syndromes, and during reperfusion ischemic injury (Figure 1).

The production of useable energy in the form of ATP is determined by the degree of oxidative phosphorylation (including nutrient supply) and oxygen availability; hence, the two are inexorably intertwined. Major determinants of myocardial oxygen demand are heart rate, blood pressure, and myocardial wall tension, in turn influenced by preload, afterload, and contractility. Since myocardial oxygen extraction from coronary arterial blood at rest is normally high, about $75 \%$ of arterial oxygen content, ${ }^{68}$ adjustments in oxygen extraction cannot correct an imbalance. Physiological increases in myocardial oxygen needs are normally provided by rises in coronary blood flow.

\section{Coronary autoregulation}

Ability of coronary arteries to increase flow to meet myocardial metabolic demand, called coronary flow reserve, is about 4-6 times the resting value at maximum dilatation of the coronary arteries, ${ }^{68,69}$ which can be somewhat expanded pharmacologically. Coronary autoregulation is a complex phenomenon with many regulating variables. ${ }^{70}$ Superimposed upon the hierarchy are the influences of disease upon each variable - atherosclerosis, ischemia, hypertrophy, alterations in autonomic nerve function, endothelial function, electrophysiology, etc. ${ }^{71}$ Up to $95 \%$ of the resistance in coronary vessels arises within small intramural vessels, about $10 \mathrm{~nm}$ to $140 \mathrm{~nm}$ in diameter, which are not visualized during coronary angiography or multislice CT angiography, a procedure identifying epicardial arteries with diameters from a few $\mathrm{mm}$ to about $500 \mu \mathrm{m}$ (arterioles with a diameter $<100 \mu \mathrm{m}$ and prearterioles with diameters from $\sim 500 \mu \mathrm{m}$ to $\sim 100 \mu \mathrm{m}$

Table 2 Classifications of functional capacity and severity in angina patients

\begin{tabular}{|c|c|c|}
\hline $\begin{array}{l}\text { Class (limitation } \\
\text { of normal activity) }\end{array}$ & $\begin{array}{l}\text { New York Heart Association Functional } \\
\text { Classification (NYHA) }\end{array}$ & $\begin{array}{l}\text { Canadian Cardiovascular Society Severity } \\
\text { Classification (CCS) }\end{array}$ \\
\hline Class I (Minimal/No limitation) & $\begin{array}{l}\text { Heart disease exists with no symptoms or } \\
\text { limitation of physical activity. Ordinary physical } \\
\text { activity does not cause angina, fatigue, } \\
\text { palpitation, or dyspnea that limit activity. }\end{array}$ & $\begin{array}{l}\text { Ordinary physical activity (such as walking or } \\
\text { climbing stairs) does not cause angina. Angina } \\
\text { may occur with strenuous rapid or prolonged } \\
\text { exertion at work or recreation. }\end{array}$ \\
\hline Class II (Mild/Slight limitation) & $\begin{array}{l}\text { There is slight limitation of physical activity. } \\
\text { Comfortable at rest, but ordinary physical activity } \\
\text { results in angina, fatigue, palpitation, or dyspnea. }\end{array}$ & $\begin{array}{l}\text { Angina may occur with } \\
\text { - walking or climbing stairs rapidly; } \\
\text { - walking uphill; } \\
\text { - walking or stair climbing after meals or in the } \\
\text { cold in the wind or under emotional stress; } \\
\text { - walking more than } 2 \text { blocks on the level at a } \\
\text { normal pace and in normal conditions } \\
\text { - climbing more than I flight of ordinary stairs } \\
\text { at a normal pace and in normal conditions }\end{array}$ \\
\hline Class III (Severe/Marked limitation) & $\begin{array}{l}\text { Patients have marked limitation of physical activity. } \\
\text { Comfortable at rest, but less than ordinary activity, } \\
\text { such as walking } 20-100 \mathrm{~m} \text {, causes fatigue, } \\
\text { palpitation, or dyspnea. }\end{array}$ & $\begin{array}{l}\text { Angina may occur after } \\
\text { - walking I-2 blocks on the level } \\
\text { - climbing I flight of stairs in normal conditions } \\
\text { at a normal pace }\end{array}$ \\
\hline Class IV (Extreme limitation) & $\begin{array}{l}\text { Severe limitation; unable to carry out any physical } \\
\text { activity without discomfort. Angina and/or symptoms } \\
\text { of cardiac insufficiency may be present at rest. } \\
\text { If any physical activity is undertaken, discomfort } \\
\text { is increased. Usually self-confined to bed or a chair. }\end{array}$ & $\begin{array}{l}\text { Angina may be present at rest. Inability to } \\
\text { perform any physical activity without } \\
\text { discomfort. }\end{array}$ \\
\hline
\end{tabular}


Table 3 Exercise capability corresponding to Canadian Cardiovascular Society Functional Classifications

\begin{tabular}{|c|c|c|}
\hline $\begin{array}{l}\text { Functional } \\
\text { class }\end{array}$ & $\begin{array}{l}\text { Exercise } \\
\text { tolerance (METs) }\end{array}$ & Approximate activity level \\
\hline 1 & $7-8$ & $\begin{array}{l}\text { Strenuous: } \\
\quad \text { Jogging, I mile in } 12 \text { min }\end{array}$ \\
\hline II & $5-6$ & $\begin{array}{l}\text { Vigorous: } \\
\text { Brisk walking, I mile in } 15 \text { min; } \\
\text { Slow jogging, I mile in } 13 \text { min }\end{array}$ \\
\hline III & $3-4$ & $\begin{array}{l}\text { Moderately vigorous: } \\
\text { Walking at a brisk pace, } \\
\text { I mile in } 20 \text { min }\end{array}$ \\
\hline IV & $\mathrm{I}-2$ & $\begin{array}{l}\text { Extremely light activity: } \\
\text { Minimal ADL, walk at } \\
\text { I mile per } \mathrm{hr}\end{array}$ \\
\hline
\end{tabular}

are below the resolutions of angiography and are not visualized).

About $5 \%$ of the resistance that determines coronary blood flow arises within the conductive epicardial coronary arteries. Resolution limitations of coronary angiography preclude assessment of pathology in the important microvascular bed, where alterations are common in ischemic heart disease, hypertension, diabetes, and autoimmune vascular pathology. The microvascular bed may respond to therapies differently than epicardial vessels. ${ }^{72}$ In considering that about $30 \%$ of patients referred for coronary angiography have normal or nonactionable reports, it is understood that the vast microvascular bed has not been evaluated. When angiography is used to assess accuracy of stress perfusion or echocardiographic testing, these limitations are pertinent. ${ }^{73}$ Measurement of blood flow using positron emission tomography is a useful tool in assessing coronary dynamics, especially in combination with other imaging techniques. ${ }^{74}$ A more aggressive stance in treating ischemic heart disease (IHD) requires an improved, detailed understanding of the microvasculature.

In patients with stable angina, a fixed reduction in the diameter of coronary arteries by at least $70 \%$ dictates an obligatory reduction in coronary blood flow in one or more coronary arteries. The inability to increase oxygen extraction or coronary blood flow, together with elevated myocardial energy demand, leads to anginal pain, variably accompanied by panoply of metabolic, electrophysiologic,

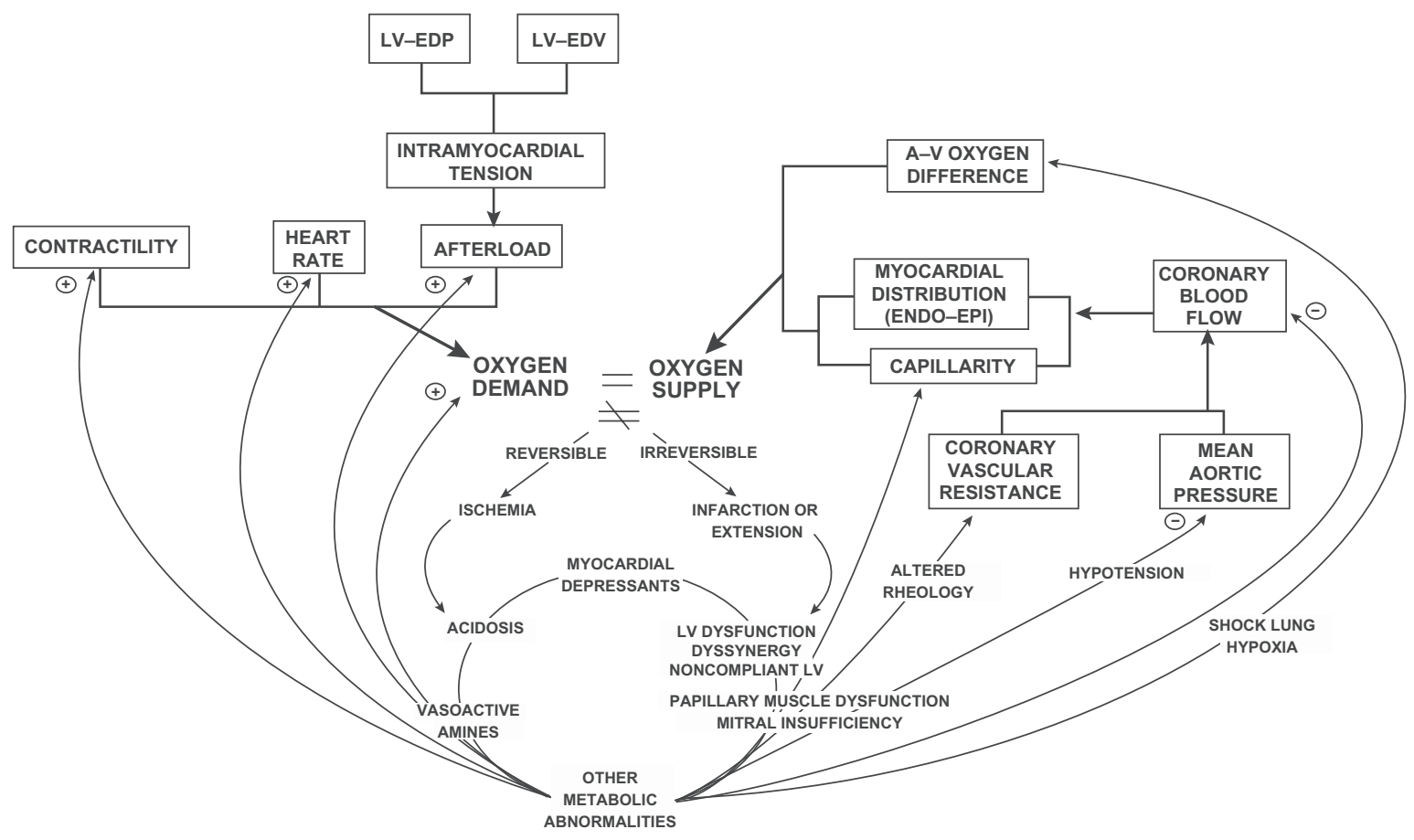

Figure I Global relationships and positive feedback loops relating to the inequality of myocardial oxygen supply and demand.

Many of the global relationships and positive feedback loops relating to the inequality of myocardial oxygen supply and demand have not changed in many years, although molecular, electrophysiological, conceptual, and technological advances have been considerable. Myocardial energy imbalance is central to all ischemic syndromes: angina, myocardial infarction, and cardiogenic shock. The variables determining myocardial oxygen supply (right) are altered by negative feedback loops from complications of poor left ventricular function (center, lower cycle). Those factors affecting myocardial oxygen demand (left, as heart rate, afterload, preload, contractility) are altered by positive feedback loops from those events perpetuating systemic features. An increase in left ventricular end-diastolic pressure (LV-EDP) or volume (LV-EDV) increases preload according to LaPlace's Law. Both the negative feedback on oxygen supply and the positive feedback on oxygen demand tend to further the inequality between the two and may jeopardize poorly perfused myocardial tissue. When ischemia progresses beyond the reversible stage of angina and myocardial necrosis follows, well-known hemodynamic, metabolic and mechanical sequellae may occur. Reproduced with permission from Kones, $1973 .{ }^{65}$ 
and hemodynamic consequences. Most events that trigger angina do so by changing myocardial oxygen demand, viz, increases in heart rate (jogging, sexual activity), afterload (doing a difficult bench press, not taking blood pressure medication), preload (consumption of a sodium-loaded pizza by a patient with heart failure and CAD), or contractility (in part, watching an exciting sports event or explosive anger with subsequent catecholamine discharge). Similarly, the beneficial effects of most maneuvers that relieve angina may be explained through corrective alterations in the determinants of myocardial oxygen supply and demand.

Endothelial dysfunction within atherosclerotic coronary arteries is abnormal, and nitric oxide production may be reduced and contribute to myocardial oxygen imbalance.

\section{Clinical pathology}

Over the past few years, an important distinction between the pathology of acute and chronic coronary syndromes has been made. In the patient with chronic coronary artery disease and fixed obstructive coronary lesions, sudden increases in myocardial oxygen demand, usually due to effort, in face of the inability to raise myocardial blood flow and oxygen supply, result in a transient myocardial energy imbalance and demand ischemia. The fixed areas of stenosis responsible are those which are likely to be seen on coronary angiography. In contrast, the majority of patients with an acute coronary syndrome suffers sudden reduction of coronary blood flow due to a discrete plaque event: rupture, erosion, or hemorrhage in a vulnerable plaque. ${ }^{75}$ A physical disruption in the plaque exposes platelets to collagen, initiating adhesion and aggregation, while tissue factor in plaque induces coagulation, and thrombus formation ensues with variable degrees of arterial obstruction. Vulnerable plaques may not be visualized during coronary angiography. Subclinical microembolism, smooth muscle hyperreactivity, and endothelial dysfunction may also contribute to progression of the syndrome. Many fatal intraarterial occlusions arising from plaque rupture do not occur at highly stenotic areas in coronary arteries. After myocardial infarction, since prognosis is significantly determined by the amount of muscle destroyed during ischemia/reperfusion, ${ }^{66,76}$ ensuring vessel patency and limiting injury to preserve myocardium are the overriding concerns.

Not every plaque disruption causes a total arterial occlusion or even clinical manifestations. Rather, the process is ongoing, involving inflammation, thrombosis, reabsorption of thrombus, fibrosis and remodeling of the plaque over time that determines whether coronary blood flow will continue unimpeded. The processes of thrombus dissolution, organization, plaque cell and lipid accumulation and synthesis of extracellular matrix cannot be predicted. An inflamed plaque with intense oxidative stress may continue to enlarge its lipid pool and accumulate inflammatory cells that produce excessive amounts of protease, ${ }^{77}$ resulting in a thin, friable, fibrous cap. The metalloproteinases in particular, expressed by macrophages and smooth muscle cells within plaques, degrade matrix collagen and elastin. In contrast, the plaque may stabilize and remodel inward during healing, decreasing its lipid pool, accumulate extracellular matrix, thicken its fibrous cap, and maintain a variably patent lumen. Alternatively, vulnerable plaques may rupture, heal, become relatively stable, but then shrink (negative remodeling) causing stenosis and low blood flow requiring revascularization. ${ }^{78}$ Lesion evolution and progression include organizing thrombi from otherwise lethal ruptures that may remodel and heal well. Outward expansion of evolving plaque (positive remodeling) may limit luminal encroachment, but is paradoxically associated with vulnerable unstable lesions containing large lipid cores rich in macrophages. The lesion considered most vulnerable is the thin-cap fibroatheroma with a large necrotic lipid core $(>34 \%$ of plaque area) and a thin fibrous cap (thickness $<65 \mu \mathrm{m}$ ). However, plaque remodeling is heterogeneous, involving intra-plaque hemorrhage and erosions of fibrous plaques. Recent information suggests that erosions rather than ruptures and may occur in the young, particularly women, who succumb to sudden coronary death. ${ }^{79}$ Erosions may be even less identifiable on stress testing and coronary angiography, and may result from repeated coronary vasospasm. Distal microembolization as a later complication of thrombosis is also of interest. ${ }^{80}$

Differences in plaque from patients with chronic stable angina and acute myocardial infarction have been reported using optical coherence tomography (OCT) imaging to assess plaque vulnerability. ${ }^{81}$ Acute myocardial infarction (AMI) survivors who were undergoing percutaneous interventions and those with stable lesions in multiple vessels had OCT images performed of infarct-related lesions or lesions slated for revascularization, as well as noninfarct-related and nontarget lesions. OCT images found intracoronary thrombus in all patients with AMI, and none in stable angina patients. Plaque rupture was identified in $77 \%$ of AMI patients, but only in $7 \%$ of stable angina patients. Thin-cap fibroatheroma were much more common in the AMI patients, not only in infarct-related culprit lesions, 
but in others as well. The authors concluded that thin caps were part of a diffuse inflammatory process in patients with acute events. Rates of plaque rupture in noninfarct-related lesions in AMI patients and nontarget lesions in stable angina patients were similar.

The myocardial oxygen imbalance of chronic stable angina is characteristically reversible short term and unassociated with myocardial necrosis. In contrast, the extent of the imbalance in acute coronary syndromes generally produces muscle cell death. To help begin decide which it is, even imperfectly, the American College of Cardiology/ American Heart Association (ACC/AHA) guidelines advise a resting electrocardiogram (ECG) be done in all patients with symptoms of angina. ${ }^{59}$ The ECG will be either normal or nondiagnostic about half the time, and false positive and negative findings in patients with angina abound. In half of such patients with a normal resting ECG, one recorded during chest pain may reveal a significant change. Even advanced CAD may be present with a normal ECG.

Interventions that reduce cardiometabolic risk, to be discussed in Part II of this review, may promote plaque stabilization by lowering inflammation, oxidation, and suppress the thrombotic cascade. Many nonpharmacological and some pharmacological treatments, especially statins, are pleiotropic in the sense that they not only improve lipid profiles, but also act in other ways to impede inflammation and destructive events. ${ }^{82}$

\section{Pretest stratification and probability of ischemia}

The three elements of typical angina include

a. substernal discomfort with location, characteristics and duration as discussed above,

b. provocation by effort or emotional stress, and

c. relief by rest or nitroglycerin.

The likelihood that a patient will have a firm diagnosis of CAD or obstructive lesions on coronary angiography from the clinical description of chest pain varies according to age, sex, and number of these three typical elements in the presentation. For instance, at age 45 , if the history contained all three criteria, $87 \%$ of men would have CAD, but only $55 \%$ of women. ${ }^{59,83}$ If the history contained two elements, ie, were atypical, these would be $51 \%$ and $22 \%$, respectively. If the chest discomfort described had none of the three elements, ie, were noncardiac, $13 \%$ of men and $3 \%$ of women would have CAD.

A few patients with obstructive CAD in fact would be missed clinically. Women have significantly less obstructive
CAD than men at the same age, and even when the history is negative for ischemia, there will be some patients who will have $\mathrm{CAD}$ in all groups.

At age 65, if all three elements of typical angina are present, $94 \%$ of men and $86 \%$ of women will have CAD. If no elements are present, ie, the chest pain is noncardiac, $27 \%$ of men and $14 \%$ of women will have CAD. As age increases, the correlation between the number of typical elements and diagnosis rises. As women age, especially beyond menopause, a greater proportion of those presenting for care will have demonstrable obstructive lesions than younger women.

\section{The probability of ischemic heart disease}

An assessment of the pretest probability of ischemic heart disease (IHD) is required for a decision about further testing.

If pain lasts $>20$ min at rest, reproduces pain previously documented as angina, and/or there is associated transient mitral regurgitation, diaphoresis, hypotension, or pulmonary rales, the probability of ischemia is high.

If there is new ST-segment deviation $\geq 0.5 \mathrm{~mm}$, T-wave inversion $\geq 2 \mathrm{~mm}$, new left bundle branch block or a serious ventricular arrhythmia, an ischemic origin is likely.

Elevations in cardiac biomarkers indicate myocardial necrosis and reclassify the patient by definition.

Features suggesting an intermediate probability of ischemic origin include absence of the above, pain $>20 \mathrm{~min}$ but abated with rest or nitroglycerin, male gender, age over 70 years, presence of diabetes, extracardiac vascular disease, fixed Q waves, and resting ST depression $\leq 1 \mathrm{~mm}$ in multiple lead groups. While the presence of left ventricular hypertrophy somewhat raises probability of associated ischemia, it is not diagnostic. Similarly, while the finding of several traditional risk factors is of interest and to be weighed, severe CAD may be present without them.

Features arguing for a low likelihood of an ischemic origin exist if

a. none of the findings above are present,

b. the patient has used cocaine prior to the episode or there is a documented history of recurrent panic attacks and/ or hyperventilation with similar pain,

c. there is chest wall tenderness, and/or

d. the ECG is normal, shows T-wave flattening, or T-wave inversions in leads with dominant $\mathrm{R}$ waves. ${ }^{84}$

None of these features are diagnostic.

Placing great predictive value upon one feature of the presentation may lead to a diagnostic error, for without a coronary angiogram, the possibility of obstructive CAD 
always remains open. New angina may also occur in patients who have histories of common diseases well known to mimic angina, such as GERD, esophageal spasm, peptic ulcer, and cholecystitis, all of which may be indistinguishable clinically. Although the differential diagnosis is familiar to physicians, errors remain a frequent subject of lawsuits. Up to $12 \%$ of patients who are discharged from emergency departments (EDs) with a noncardiac diagnosis have had or will sustain an AMI.

New imaging techniques, especially in EDs, and biomarkers currently available for both AMI and rule out diagnoses now offer greater assistance in improving accuracy of diagnosis and treatment. ${ }^{85,86}$ For instance, the use of new high sensitivity troponin assays, hs-cTnT, properly used, provide sooner exclusion and potentially improved identification of myocardial necrosis. ${ }^{87-91}$ In addition, the increasing use of chest pain units in hospitals may improve patient outcomes and possibly reduce inappropriate hospital admissions. ${ }^{92-94}$

By following applicable guidelines and pursuing objective data to confirm clinical impressions, the careful physician will avoid many of the common pitfalls in clinical decision making leading to misdiagnosis and/or mistreatment.

\section{Diagnostic studies}

The choice of how to proceed depends upon the individual patient, and also reflects the two objectives of noninvasive testing. For those with new onset chest pain, the need for diagnosis predominates, and the question to be answered is whether or not ischemia due to obstructive atherosclerotic lesions is present. In established patients, the dominant issue is risk stratification and whether coronary angiography is needed for further management.

\section{Exercise ECG testing}

In general, most patients - all but those with extremely low probabilities of an ischemic origin of their chest pain - should receive graded exercise testing, particularly if the resting ECG is normal. The Bruce protocol and Duke Treadmill Score are commonly used. Patients must be able to exercise adequately, and be free of confounding features precluding interpretation on the resting ECG.${ }^{95}$ The test may reveal typical changes of ischemia on the ECG in association with chest pain, which clarifies the diagnosis, and the patient's exercise capacity may provide further direction in treatment. Together with the Duke Treadmill score, exercise testing gives predictive information concerning survival. Exercise tests are most valuable when there is an intermediate probability of $\mathrm{CAD}$, according to Bayesian theory, and are recognized by the ACC/AHA Task Force on practice guidelines as an important asset in such patients for clinical decision making. ${ }^{59}$ However, when the probability of CAD is high, the exercise test may be indicated for risk stratification, prognosis and clinical direction. ${ }^{83}$

Exercise tests are not indicated in patients with preexcitation syndromes, those that are being paced, have complete left bundle branch block (LBBB), over $1 \mathrm{~mm}$ of ST segment depression at rest, a myocardial infarction within the previous two days, unstable angina, pericarditis, active ECG changes, severe aortic stenosis or lung disease, ongoing poorly controlled arrhythmias, uncontrolled hypertension, active cerebral ischemia or embolic phenomena, advanced lung disease, heart failure, aortic dissection, myocarditis/endocarditis, or other major unresolved problems. Generally $\beta$-blockers, nodal blockers, and nitrates are discontinued about two days before testing and digoxin about one week beforehand. The test should be aborted if there is chest pain, severe dyspnea, dizziness or near syncope, fatigue, ST elevation $\geq 1 \mathrm{~mm}$ without diagnostic Q waves, ST depression $\geq 2 \mathrm{~mm}$, fall in systolic $\mathrm{BP}>10 \mathrm{mmHg}$, or a ventricular arrhythmia.

An exercise test is positive for ischemia if any of the following occur:

- New flat or downsloping ST-segment depression $\geq 1 \mathrm{mV}$ below the baseline, at least $0.06-0.08 \mathrm{sec}$ after the QRS complex J-point in multiple leads, the most reliable indicator of ischemia. ${ }^{95}$ If it appears during a low workload, prognosis may be worse.

- New ST-segment depression at the start of exercise (within $3 \mathrm{~min}$ );

- ST-segment depression persists beyond 6 min of the recovery phase;

- Fall in systolic blood pressure during exercise (normally this rises because of increased stroke volume);

- Development of acute heart failure or sustained ventricular arrhythmias. Significant ventricular ectopy during recovery has greater significance than ectopy during exercise.

- Development of characteristic chest pain during exercise;

- Inability to exercise more than 2 min on a cardiac basis.

The exercise test is imperfect, with false-negative and false-positive results one-third of the time, but is useful, inexpensive, widely available, simple and practical. For instance, if the test is positive in a male with a history of classical angina, he develops chest pain during the test, and is over 50 years of age, there is a $98 \%$ probability 
he has advanced CAD. On the other hand, with limited sensitivity, a negative test strongly argues against more ominous forms of CAD such as three-vessel or left anterior descending coronary obstruction, but certainly does not exclude CAD. The sensitivity and specificity is $68 \%$ and $77 \%$ respectively. ${ }^{96,97}$ Specificity is reduced in middleaged females, with a false positive rate of $17 \%$ compared to $11 \%$ in males. ${ }^{98}$

Some investigators believe the overall accuracy of ST segment depression on exercise ECG testing is only about $65 \% .{ }^{99,100}$ For this reason an additional scoring system using three independent variables: exercise time; ST segment deviation; and angina index has been used extensively, and was incorporated into the ACC/AHA Guidelines for exercise testing. ${ }^{96}$ The Duke Treadmill Score (DTS) quantitates risk, assists with prognosis, and is calculated as follows ${ }^{101}$

DTS $=$ Exercise time $(\mathrm{min})-$

$[5 \times \mathrm{ST}$ segment deviation $(\mathrm{mm})]-$

$[4 \times$ angina index $]$

where the angina index is

0 if no angina occurs anytime,

2 if angina is the reason for stopping the exercise test, and

1 if angina occurs during the test or during the recovery period.

If DTS is $\geq 5$, risk is low, the associated 4 year survival is $99 \%$, and such patients should be managed medically. If DTS is $<(-10)$, risk is high, the 4 year survival is $79 \%$ with an average mortality of $5 \%$, and such patients should be referred for coronary angiography. Approximately 4\% of patients have high risk DTS, and about two-thirds of patients have low risk DTS (Table 4). ${ }^{101}$

Patients with overtly positive exercise tests should undergo cardiac catheterization with revascularization in mind. Further indications, precautions, contraindications, caveats, interpretation criteria, and details of exercise testing are given in the full ACC/AHA guidelines. ${ }^{96,102}$

\section{Stress imaging}

Stress imaging includes myocardial perfusion, stress echocardiography, and other techniques.

Table 4 Duke Treadmill scores (DTS), survival, and annual mortality

\begin{tabular}{lllll}
\hline Risk level & DTS & $\begin{array}{l}4 \text { Year } \\
\text { survival (\%) }\end{array}$ & $\begin{array}{l}\text { Overall } \\
\text { survival (\%) }\end{array}$ & $\begin{array}{l}\text { Annual } \\
\text { mortality (\%) }\end{array}$ \\
\hline Low & $\geq 5$ & 99 & 62 & 0.25 \\
Moderate & $-10-+4$ & 95 & 34 & 1.25 \\
High & $<-10$ & 79 & 4 & 5.0 \\
\hline
\end{tabular}

Compared to exercise electrocardiography, perfusion imaging with ${ }^{201}$ thallium or ${ }^{99} \mathrm{~m}$ technetium-sestamibi raises sensitivity, but prognostic value is less established. ${ }^{102}$ Perfusion imaging is particularly useful when the resting ECG is abnormal, in women because of false positives on stress $\mathrm{ECG},{ }^{103}$ and in symptomatic patients who have had prior revascularization, reversible areas of ischemia may be quantified and localized to specific areas of the myocardium. ${ }^{104}$

${ }^{99 m}$ Technetium-sestamibi produces better and faster images with decreased attenuation, has lower sensitivity for viable myocardium than ${ }^{201}$ thallium, and is more expensive.

Increased lung uptake post testing, left ventricular dilation, and multiple perfusion defects are associated with left main coronary or severe multivessel disease and should be followed by coronary angiography. Patients with two or more perfusion defects and ventricular dysfunction are also candidates for angiography. Use of perfusion imaging has been found to lower rates of hospital admission by up to $52 \%$ while evaluating acute chest pain in the emergency department. ${ }^{105}$

A number of patients who require stress testing are unable to exercise, most frequently due to peripheral vascular disease, a prior stroke, arthritis, lung disease, neurological disorders, or simply deconditioning in the elderly. In this circumstance pharmacological challenge is performed using dipyridamole, adenosine, or dobutamine. Dipyridamole and adenosine raise blood flow in healthy coronary arteries, stealing blood from myocardium served by obstructed vessels. After administration of either of these two agents the perfusion imaging study is performed. Dipyridamole may cause bronchospasm and is not used in asthmatics. Xanthines may cause false-negative studies. Adenosine may produce flushing, dyspnea, chest pain, and bradyarrhythmias, and cannot be used in a patient with sick sinus syndrome or high grade AV block. Alternatively, a graded infusion of dobutamine may be used to raise myocardial oxygen demand prior to perfusion imaging, and is useful in patients who cannot raise their heart rates adequately during exercise.

If the initial evaluation of the patient with angina suggests heart failure, pulmonary hypertension, valve disease or hypertrophic cardiomyopathy, echocardiography may be considered. In addition, baseline or follow-up measurement of systolic or diastolic function may be of value in rehabilitation. Echocardiography may be also used with or without exercise or pharmacological stress to reveal 
segmental wall motion abnormalities associated with ischemia. Stress echocardiography is more sensitive than stress electrocardiography. Exercise makes normal myocardium hyperdynamic, but ischemic walls become hypokinetic or akinetic. Accuracy is comparable to perfusion imaging, not as widely available, and less expensive. Since it is the only stress technique that evaluates ventricular function, valve disease, and cardiac dimensions, it has special value in patients with aortic stenosis, idiopathic hypertrophic subaortic stenosis, or changing murmurs.

Magnetic resonance coronary angiography (MRCA) is an exciting and promising addition to cardiac imaging. ${ }^{106-109}$ While useful in the emergency department for triage, information derived is primarily anatomic rather than functional or predictive; present limitations will no doubt be improved with further research and development. ${ }^{110}$ Both MRCA and computed tomographic coronary angiography (CTCA) are effective as rule-out techniques but remain imperfect. Radiation exposure and need for contrast with CTCA detracts from long term interest. An excellent authoritative review of both techniques is available, ${ }^{111}$ and recent criteria for appropriate cardiac radionuclide imaging with further details are summarized in a consensus statement. ${ }^{112}$

Current guidelines clearly indicate that in most patients a noninvasive test should be performed prior to coronary angiography, but in about $15 \%$ of cases, it is not done.

Table 5 has a comparison of sensitivity, specificity, and predictive accuracy of noninvasive tests currently used for diagnosis and stratification of patients suspected of having coronary artery disease.

\section{Risk stratification after noninvasive testing}

Evidence based guidelines stratify patients into three categories: high, intermediate, and low, for clinical decision making and advising patients about their choices. ${ }^{59}$ Inclusion criteria for these categories based on noninvasive testing are summarized in Table 6.

\section{Coronary angiography}

Coronary angiography remains the gold standard for the diagnosis of CAD, and defines the location(s) as well as the extent of the disease. As mentioned, it should be performed in patients with angina who have a markedly positive stress test, but also in those in whom testing strongly suggests left main coronary artery or three-vessel disease. Other indications include patients who may have a nonatherosclerotic cause of ischemia such as a coronary arterial anomaly, those who have frequent readmissions for chest pain, who are resistant to medical therapy (disabling angina despite optimal evidence based medical management), who have undergone prior revascularization procedures, those with indeterminate stress tests and clinical features of severe CAD, those with heart failure, some patients who are unable to proceed with noninvasive evaluation, or whose occupation demands a definitive diagnosis.

Coronary angiography also refines prognosis. In patients referred for angiography and subsequently treated medically, in those who had three-vessel disease, the 12 year survival was $40 \%$; in those with two-vessel disease, it was $59 \%$; in patients with one vessel obstructed, 74\%; and in patients with normal coronary arteries, there was $91 \%$ survival over the same period. ${ }^{113}$ Extent and location of obstruction may be precisely quantitated; when lesions are proximal, prognosis is worse. Simultaneously, left ventricular function, a critical determinant of prognosis, may also be accurately characterized. Coronary angiography provides precise information about two of the four most important predictors of long term survival: left ventricular systolic function and extent and distribution of obstructions. Unfortunately, however, it does not quantify plaque stability and probability of rupture, a third determinant of outcome and a topic of great current interest. The fourth determinant of risk and prognosis of

Table 5 Tests used for diagnosis and prognosis in ischemic heart disease*

\begin{tabular}{llll}
\hline Test type & Sensitivity (\%) & Specificity (\%) & Predictive accuracy (\%) \\
\hline Exercise ECG & 68 & 77 & 73 \\
Duke Treadmill score & - & - & 80 \\
${ }^{201}$ Thallium perfusion scan & 85 & 85 & 85 \\
$99 m$ technetium-sestamibi/SPECT & 88 & 72 & 80 \\
Adenosine SPECT & 90 & 82 & 85 \\
Exercise echocardiography & 85 & 81 & 80 \\
Dobutamine echocardiography & 88 & 84 & 86 \\
Computed tomography: Electron beam & 60 & 70 & 65 \\
tomography (EBCT) calcium score & & &
\end{tabular}

"Data vary according to studies included and characteristics of patient group studied, eg, number of coronary vessels involved, etc. 
Table 6 Risk stratification based upon noninvasive testing in patients suspected of having ischemic heart disease

\begin{tabular}{|c|c|c|}
\hline Risk level & Annual mortality rate $(\%)$ & Clinical indicators \\
\hline \multirow[t]{11}{*}{ High } & $>3$ & - Severe resting left ventricular dysfunction (LVEF < 35\%) \\
\hline & & - High risk Duke treadmill score $(\mathrm{DTS}=(-\mathrm{II}))$ \\
\hline & & - Severe exercise left ventricular dysfunction (exercise LVEF < 35\%) \\
\hline & & - Large stress induced perfusion defect, particularly if anterior \\
\hline & & - Multiple stress induced perfusion defects of moderate sizes \\
\hline & & - Large, fixed perfusion defect with LV dilation or increased lung uptake (thallium-20I) \\
\hline & & $\begin{array}{l}\text { - Stress induced moderate perfusion defect with LV dilation or increased } \\
\text { lung uptake (thallium-20I) }\end{array}$ \\
\hline & & - Echocardiographic wall motion abnormality (involving $>2$ segments) \\
\hline & & developing at low dose of dobutamine $(=10 \mathrm{mg} / \mathrm{kg} / \mathrm{min})$ or at a low \\
\hline & & - Heart rate $(<120$ beats $/ \mathrm{min})$ \\
\hline & & - Stress echocardiographic evidence of extensive ischemia \\
\hline \multirow[t]{6}{*}{ Intermediate } & $1-3$ & - Mild/moderate resting left ventricular dysfunction (LVEF = 35\%-49\%) \\
\hline & & - Intermediate risk Duke treadmill score $[\mathrm{DTS}=(-\mathrm{II})$ to $(<5)]$ \\
\hline & & - Moderate stress induced perfusion defect without LV dilation or increased \\
\hline & & lung intake (thallium-20I) \\
\hline & & - Limited stress echocardiographic ischemia with a wall motion \\
\hline & & abnormality only at higher doses of dobutamine involving I-2 segments \\
\hline \multirow[t]{4}{*}{ Low } & $<1$ & Low risk treadmill score $(\mathrm{DTS}=5)$ \\
\hline & & Normal or small myocardial perfusion defect at rest or with stress \\
\hline & & Normal stress echocardiographic wall motion or \\
\hline & & no change of limited resting wall motion abnormalities during stress \\
\hline
\end{tabular}

Abbreviations: LV, left ventricular; LVEF, left ventricular ejection fraction; DTS, Duke treadmill score.

patients with ischemic heart disease is general health and extra-coronary comorbidity. ${ }^{59}$

Use of coronary angiography as a screen, especially in symptom free patients, has been criticized because of low diagnostic yield, with up to $38 \%$ of "negative" studies, in view of the radiation exposure and potential adverse events. ${ }^{199}$ However, a normal result does not imply that a procedure is not indicated or is overutilized. When used appropriately according to current decision guidelines, both the negative as well as the positive information obtained is necessary for optimal management. Such discussions about overuse of coronary angiography do not apply to the urgent evaluation of chest pain, or to patients with known CAD, in whom potential benefits clearly outweigh potential procedural risks. The high frequency of false negative coronary angiograms in some subsets of patients only underscores the need for improving the diagnosis of obstructive $\mathrm{CAD}$, following guidelines, and continuing the search for additional data and new techniques.

\section{Gender differences in CAD}

Gender differences in CAD are now acknowledged and recognized, but not yet fully characterized or incorporated.

Angina is the most common symptom of IHD in women. Age, gender, ethnic, regional and socioeconomic differences in patients with chest pain and heart disease, spawning inequalities or disparities in care, have long been neglected, and remain only partially addressed open issues, requiring further research and action. ${ }^{14,115}$ Etiology, risk factors, pathogenesis, presentation, evaluation, diagnostic testing, physicians' choice of treatment, response to therapy, and outcomes are all gender specific. ${ }^{116}$ Even initiation or restarting drugs for secondary prevention lags in women. Gender differences in presentation of chest pain and angina are important and merit greater awareness among all members of cardiac service teams. Moreover, women have a 20 percent higher prevalence of stable angina than men. ${ }^{117}$

The typical triad of angina includes effort induced substernal pressure or tightness and relief upon rest or use of nitroglycerin. Patients with atypical histories and symptoms, especially women, ${ }^{116,118,119}$ are more likely to be misdiagnosed and under treated. Women with acute coronary syndromes (ACS) have more dyspnea, indigestion, nausea and vomiting, weakness, and back pain than men. ${ }^{120,121}$ In a recent study, a significantly greater number of men presenting with chest pain $(17 \%)$ had a diagnosis of CAD than women (13\%), and chest pain lasting from 1-12 hours in women was more likely to be due to CAD than in men, who reported a shorter episode (30-60 min). ${ }^{122}$ Another series of 112 women and 144 men admitted for ACS confirmed greater reporting of indigestion, palpitations, nausea, numbness of the hands, and fatigue in women. ${ }^{123}$ The vagueness and nonspecific nature of these symptoms poses difficulties in clinical decision making. 
Ischemic heart disease is a different disease in women and is strongly dependent upon stage of life; in young women, differences are even greater (Table 7).

Evaluation, appropriateness of treatment, and research inequality in women, with respect to atherosclerosis progression, relief of symptoms and ultimate prognosis, are concerns that begin with risk factor differences between genders ${ }^{183}$ and persist even beyond percutaneous coronary intervention (PCI) ${ }^{184}$ For instance, a gender delay in emergency medical services in Dallas County, Texas was dismissed as minor, but women were actually $52 \%$ more likely than men to be delayed $15 \mathrm{~min}$ or more from the time emergency medical services teams arrived in response to a call and reaching a hospital, potentially involving additional myocardial cell death, critical in subsequent complication rates and prognosis. ${ }^{161,162}$ Interestingly, during an evaluation of gender differences in the management and prognosis of myocardial infarction, women had a higher body mass index and more diabetes, renal dysfunction and depression, but less chronic lung disease, smoking history, cancer, and fewer prior myocardial infarctions than men. ${ }^{185}$

Cardiac electrophysiological differences between men and women are well known. ${ }^{186}$ Women have longer QT intervals, and estradiol and testosterone are capable of altering portions of the cardiac action potential. Estradiol has been linked to after-depolarizations and torsades de pointes in laboratory animals. Inappropriate sinus tachycardia, more common in women, may be related to both autonomic dysregulation of the sinus node and/or an immunological disorder of cardiac $\beta$-adrenergic receptors. Significant gender differences in sudden cardiac death have been reported, including different responses to therapy. Despite equal benefits derived from such devices, utilization of implantable cardioverter defibrillators and cardiac resynchronization therapy is lower in women. ${ }^{187}$

Women enjoy premenopausal protection against IHD, which may be blunted by diabetes, multiple risk factors, and a myocardial infarction. Why women, with a higher prevalence of risk factors, clinically more difficult angina, fewer obstructive coronary lesions, and milder myocardial infarctions have poorer clinical outcomes, most accentuated in younger women, remains uncertain. ${ }^{14,188}$ Another feature of the paradox is the higher incidence of heart failure in the face of better left ventricular systolic function, as compared with men, before PCI. Fundamental biological differences between sexes, especially microvascular dysfunction, with smooth muscle, endothelial, and autonomic nervous system components, appear to contribute to ischemic physiology in women (Table 7). However, as attractive as the endothelial and microvascular dysfunction hypothesis is, supporting data are not yet robust. Failure to follow guidelines equally, ie, gender bias in invasive procedures, accounts for only a part of the difference. ${ }^{189,190}$

Perhaps the lack of a single cohesive explanation of differences between the pathophysiology of IHD in women and men contributes in a small way to gender disparities, since the message cannot be underpinned with a large, single arrow. Nonetheless, women generally do not receive sufficiently intense therapy when treated medically for CAD, ${ }^{189,191}$ nor after AMI, ${ }^{192}$ with or without obstructive CAD. However, women with chronic stable angina and CAD most certainly benefit from, and deserve, full medical therapy just as do men, ${ }^{193}$ and the guidelines are clear.

A meta-analysis of randomized trials compared the effects of a conservative vs an invasive strategy in women and men with acute coronary syndrome without ST-elevation. ${ }^{194}$ While high risk patients of either sex enjoyed a $20 \%$ reduction in the composite endpoint of death, myocardial infarction, or recurrent $\mathrm{ACS}$, an early invasive treatment in women with angina/ACS and negative biomarkers was associated with a $35 \%$ increase in risk of death. Men did not face this risk. These data significantly tempered enthusiasm for aggressive ACS strategies in low risk women, and ACC/AHA guidelines now recommend an invasive strategy in high risk women (the same as men), but in low risk women, a conservative strategy is advised. ${ }^{195-198}$

\section{Goals in management of the patient with angina}

There are generally three inter-related goals in managing patients with stable chronic angina:

- Limit the number, severity, and sequellae of anginal attacks, including psychological consequences, thereby increasing quality of life.

- Protect against future, potentially more lethal ischemic syndromes, such as sudden death, myocardial infarction, and cardiogenic shock.

- Lower the risk for atherosclerosis progression.

\section{Conclusion}

The diagnosis of chronic stable angina is made clinically, and is further refined by laboratory data, including electrocardiography, exercise testing, imaging, and possibly coronary angiography. Coronary artery disease, or ischemic heart disease, is the leading cause of death in the United States. Angina is one of the syndromes produced by CAD, and chest 
Table 7 Some observations of interest about angina/ischemic heart disease in women*

\begin{tabular}{ll}
\hline Category & Finding or observation \\
\hline Etiology: Cellular events & - Myocardial weight, myocyte number and volume better preserved with age \\
and the vascular bed & - Incidence of vasculitis, vasospastic disorders, Raynaud's phenomenon-, and migraine are higher in women. \\
- Autoimmune diseases, more frequent in women, ${ }^{24}$ may be linked to inflammation and/or reactivity. \\
- Increased coronary arterial reactivity is observed in women. ${ }^{125}$ \\
- Differences in microvasculature have been attributed to sex hormone/receptor variations generally. \\
- There is impairment in coronary flow reserve as judged by intracoronary response to adenosine, attributed to \\
microvascular smooth muscle dysfunction. ${ }^{126}$ \\
- Vasospastic angina is caused by coronary microvascular spasm. ${ }^{127}$
\end{tabular}

- Endothelial involvement ${ }^{128}$ and autonomic nervous system adrenergic pathways ${ }^{129}$ contribute to a vascular component to ischemic heart disease in women, although ill defined.

- Microvascular dysfunction may add a significant component to IHD in women that is not easily assessed clinically. ${ }^{126,128}$

- Ultrasound studies in obstructive CAD reveals greater microvascular disease in women and greater atheroma burden with diffuse epicardial endothelial dysfunction. ${ }^{130}$

- Endothelial dysfunction is raised in women with multiple risk factors and accelerates after menopause, ${ }^{131}$ by a factor of from 1.3 to $4.4 .^{132}$

- Increased number of endothelial progenitor cells after myocardial infarction.

- In sudden coronary death, young women have a higher proportion of erosions than ruptures in culprit vessels. ${ }^{79}$

- Aspirin lowers platelet reactivity similarly in men and women, ${ }^{133}$ but is less effective as primary prevention in women. ${ }^{134}$

- Part of the protective effect of estrogen may be mediated by increased activity of serine/threonine protein kinase (Akt), which is involved in cell survival.

Epidemiology

- More women die from CAD than from cancer, with a ratio of 4.6 to 2.6. ${ }^{135}$

- CAD mortality reductions noted recently for women are lower than for men. ${ }^{136}$

- Compared to men, the absolute number of women dying from IHD is greater.

- About $52 \%$ of women, compared to $42 \%$ of men, die of SCD prior to arriving at a hospital. ${ }^{137}$

- Recent reductions in incidence of SCD reported in men are not enjoyed by women. ${ }^{138}$

- Some epidemiological differences are believed to be hormone related.

Pathophysiology

- Microvascular dysfunction appears to be more significant in women. ${ }^{139}$

- Obstructive CAD is less frequent, LVF better preserved, ${ }^{140}$ and rates of ischemia are higher in women than men in age-matched cohorts. ${ }^{16,140,141}$

- Plaque instability, especially erosion and distal microembolization, is a greater factor in women in the evolution of coronary plaque. ${ }^{142,143}$

- Cardiac remodeling in response to ischemic cell death, overload and age are different and is better than in men.

- Incidence, prevalence, and severity of heart failure is lower in women than men, possibly due to estrogen's protective, anti-fibrotic, anti-inflammatory effects.

Risk factors

- Post menopausal rise in dyslipidemia, ${ }^{16,144,145}$ weight, ${ }^{146}$ and in the cluster of risk factors known as the MetS ${ }^{147,148}$ adds to the burden in women.

- Hypertriglyceridemia is more atherogenic in women than in men. ${ }^{149}$

- Diabetes raises CAD mortality to a greater extent in women than in men. ${ }^{150}$

- Recent reductions in CAD mortality observed in men with diabetes are not enjoyed by women. ${ }^{151}$

- Levels of CRP are higher in women than in men, beginning at puberty. ${ }^{152}$

- Benefits of statins, especially in prolonging life, continue to be debated.

Risk factor assessment

- CRP is an important risk factor in women. ${ }^{135,136}$

- Framingham Risk Scores underestimate individual risk, but do so inordinately in women. ${ }^{153-156}$

- Inclusion of CRP in risk evaluation improves risk assessment in $>40 \%$ of women classified as intermediate risk by Framingham Scores. ${ }^{157}$

Presentation

- Atypical symptoms are more frequent in women, ${ }^{158}$ with reporting influenced by male dominated original studies. ${ }^{159}$

- Women delay seeking medical care for angina ${ }^{160}$ and there is also a delay in door-to-hospital time. ${ }^{161,162}$

- Atypical presentations lead to lower calculated probabilities of obstructive CAD than in men. ${ }^{163}$

Natural history

- Symptoms are often more persistent, ${ }^{164}$ leading to higher hospital admission rates, including those for HF, ${ }^{165}$ incurring greater utilization and costs, ${ }^{166}$ thereby lowering quality of life. ${ }^{167}$

- A higher prevalence of atypical chest pain together with negative studies may create ambiguity and indecision regarding diagnosis and treatment plans as compared to men. ${ }^{164,165}$ 
Table 7 (Continued)

\begin{tabular}{|c|c|}
\hline Category & Finding or observation \\
\hline Exercise electrocardiography & $\begin{array}{l}\text { - The exercise ECG has lower specificity and sensitivity in women, }{ }^{168} \text { in part because the incidence of obstructive } \\
\text { lesions is lower than in men. } \\
\text { - For each additional MET in exercise capacity achieved in asymptomatic women being tested, mortality falls by } 17 \% .{ }^{169} \\
\text { - For each additional unit recorded in the Duke Treadmill Score, the risk of death falls by } 9 \% .{ }^{169} \\
\text { - When women cannot exercise at levels of }>5 \mathrm{MET} \text {, which is not uncommon, risk of AMI or cardiac death rises } \\
\text { about 3-fold. }{ }^{170,171}\end{array}$ \\
\hline Cardiac imaging & $\begin{array}{l}\text { - Myocardial perfusion imaging and echocardiography raise diagnostic sensitivity as compared to the exercise ECG. }{ }^{102,172} \\
\text { - Accuracy of SPECT imaging is reduced when exercise capacity is low, and hence pharmacologic stress testing is } \\
\text { recommended. }{ }^{98} \\
\text { - Since specificity may be lowered by excess fat and breast tissue to produce false positive results, higher energy }{ }^{99 \mathrm{~m} T c} \\
\text { or prone imaging minimizes artifact s and offers an advantage. }{ }^{103} \\
\text { - Stress echocardiography is accurate diagnostically }{ }^{173} \text { with a specificity of about } 76 \% \text { and sensitivity of about } 84 \% \text {, and } \\
\text { can also used for risk stratification. }{ }^{174}\end{array}$ \\
\hline Coronary angiography & $\begin{array}{l}\text { - Nearly half the women who are studied have normal ( }<50 \% \text { stenosis) coronary angiograms, }{ }^{175} \text { which also applies to } \\
\text { women with ACS. }{ }^{140} \text { Over half of those women will continue to suffer with ischemic symptoms. } \\
\text { - Among STEMI patients, } 10 \%-25 \% \text { of women have normal angiograms, compared to } 6 \%-10 \% \text { of men. }{ }^{176,177}\end{array}$ \\
\hline Treatment & $\begin{array}{l}\text { - Women are undertreated both medically and procedurally with respect to current guidelines. }{ }^{161} \\
\text { - Women are less likely to receive referrals to cardiologists by primary care providers. }{ }^{178} \\
\text { - Women have greater mortality when undergoing } \mathrm{PCl} \text { after myocardial infarctions. }{ }^{179} \\
\text { - During medical treatment, women have more disability, lower quality of life, and poorer outcomes. This is partially } \\
\text { due to bias in evaluation and treatment, but more because of innate biological differences between in men and } \\
\text { women not yet fully appreciated. } \\
\text { - When it comes time to start or resume medications for secondary prevention, women are slighted. }\end{array}$ \\
\hline Prognosis & $\begin{array}{l}\text { - Correction of endothelial dysfunction in postmenopausal hypertensive women may lower IHD events } 7.3 \text {-fold. }{ }^{180} \\
\text { - Older population, delay in presentation, less obstructive CAD, more risk factors, different testing characteristics, } \\
\text { milder AMls with higher mortalities, underutilization of guideline recommendations, more microvascular dysfunction, } \\
\text { increased adverse event rate after } \mathrm{PCI} \text {, sex difference in biomarkers, greater mortality after PCI in low risk women, } \\
\text { may all contribute to poorer prognosis in women than men. }{ }^{104} \\
\text { - In chronic stable angina, as the EF decreases, as assessed with echocardiography, risk rises and mortality worsens } \\
\text { faster in women than in men. }{ }^{181} \\
\text { - Women with obstructive CAD undergoing coronary angiography have about twice the odds of in-hospital death }{ }^{140} \\
\text { and greater mortality after AMI. }{ }^{182} \\
\text { - CRP is an important risk factor in women. }{ }^{135,136} \\
\text { - Framingham Risk Scores underestimate individual risk, but do so inordinately in women. }{ }^{153-156} \\
\text { - Inclusion of CRP in risk evaluation improves risk assessment in }>40 \% \text { of women classified as intermediate risk by } \\
\text { Framingham Scores. }{ }^{157}\end{array}$ \\
\hline
\end{tabular}

Note: "This table is by no means complete, and only contains a fraction of available resources.

Abbreviations: ACS, acute coronary syndrome; AMI, acute myocardial infarction; CRP, C-reactive protein; CAD, coronary artery disease; EF, ejection fraction; IHD, ischemic heart disease; HF, heart failure; LVF, left ventricular function; MET, metabolic equivalent task; MetS, metabolic syndrome; SCD, sudden cardiac death; STEMI, ST-segment elevation myocardial infarction.

discomfort is a commonly encountered symptom reflecting myocardial ischemia. Successful management draws upon both the science and art of medicine, but yet may challenge even the most seasoned cardiologist. New pathophysiological data, as well as conceptual and technological advances, have consistently improved patient evaluation over the past decade.

While perhaps less fashionable than topics concerning myocardial infarction/STEMI/NSTEMI, PCI, and CABG, the sheer number of patients afflicted with angina has attracted renewed interest. Independently, diagnosis, risk assessment, ability to predict prognosis, and treatment all remain imperfect.
Unfortunately, just as guideline defined targets remain unmet in the treatment of hypertension, dyslipidemia, and diabetes, significant numbers of women, and to a lesser degree, men, are also undertreated for their angina, and suffer ongoing, disabling exertional symptoms while under active medical care. Despite fundamental advances in basic science and availability of clinical outcome data, clinical inertia in following current guidelines continues to be a barrier in achieving therapeutic goals.

In the second part of this two-part series, current evidence based medical management with anti-ischemic therapy, promising novel anti-anginal agents and their potential to improve outcomes, options for treating refractory angina, 
the important role of implementing population-wide, lifestyle modification and risk reduction to lower the prevalence and burden of angina and ischemic heart disease, and current data, guidelines, and comparative performance regarding revascularization procedures in patients will be reviewed.

\section{Acknowledgment}

The author wishes to thank Michelle Delaney for her astuteness, computer skills, untiring assistance, and valuable suggestions in the preparation of this manuscript.

\section{Disclosure}

The author reports no conflicts of interest in this work.

\section{References}

1. Skalski JH. Myocardial infarction and angina pectoris in the history of Polish medicine. Pol Arch Med Wewn. 2008;118(4):243-247.

2. Iqbal J, Fox KAA. Epidemiological trends in acute coronary syndromes: understanding the past to predict and improve the future. Arch Med Sci. 2010;6(1A):S3-S14

3. Giugliano D, Ceriello A, Esposito K. The effects of diet on inflammation. J Am Coll Cardiol. 2006;48:677-685.

4. Ikeda U. Inflammation and coronary artery disease. Curr Vasc Pharmacol. 2003;1(1):65-70.

5. Heinisch RH, Zanetti CR, Comin F, Fernandes JL, Ramires JA, Serrano $\mathrm{CV}$ Jr. Serial changes in plasma levels of cytokines in patients with coronary artery disease. Vasc Health Risk Manag. 2005;1(3):245-250.

6. Ridker PM. Testing the inflammatory hypothesis of atherothrombosis: scientific rationale for the cardiovascular inflammation reduction trial (CIRT). J Thromb Haemost. 2009;7 (Suppl 1):332-339.

7. Devaraj S, Singh U, Jialal I. The evolving role of C-reactive protein in atherothrombosis. Clin Chem. 2009;55:229-238.

8. Ridker PM. Inflammation, high-sensitivity C-reactive protein, and vascular protection. Tex Heart Inst J. 2010;37(1):40-41.

9. Dewell A, Ornish D. Plant-based dietary patterns in the control of obesity and cardiovascular risk. Curr Cardiovasc Risk Rep. 2007;1:9-15.

10. Brown WV, Karmally W, Kris-Etherton P, Rudel LR. Discussion on dietary fat. J Clin Lipidol. 2009;3:303-314.

11. Lloyd-Jones DM, Hong Y, Labarthe D, Mozaffarian D, et al; on behalf of the American Heart Association Strategic Planning Task Force and Statistics Committee. Defining and Setting National Goals for Cardiovascular Health Promotion and Disease Reduction. The American Heart Association's Strategic Impact Goal Through 2020 and Beyond. Circulation. 2010;121:586-613.

12. Patel NB, Balady GJ. The Rewards of Good Behavior. Circulation. 2010;121:(6):733-735

13. Buckley B, Murphy AW. Do patients with angina alone have a more benign prognosis than patients with a history of acute myocardial infarction, revascularisation or both? Findings from a community cohort study. Heart. 2009;95:461-467.

14. Hemingway H, Shipley M, Britton A, et al. Prognosis of angina with and without a diagnosis: 11 year follow up in the Whitehall II prospective cohort study. BMJ. 2003;327:895-898.

15. Hemingway H, McCallum A, Shipley M, et al. Incidence and prognostic implications of stable angina pectoris among women and men. JAMA. 2006;295:1404-1411.

16. Gandhi MM, Lampe FC, Woo DA. Incidence, clinical characteristics, and short-term prognosis of angina pectoris. Br Heart $\mathrm{J}$. 1995; 73:193-198

17. Berecki-Gisof J, Humphreyes-Reid L, Wilson A, Dobson A. Angina symptoms are associated with mortality in older women with ischemic heart disease. Circulation. 2009;120:2330-2336.
18. Meijs FML, Bots ML, Cramer MJM, et al. on behalf of the SMART Study group. Unrecognized myocardial infarction in subjects at high vascular risk: prevalence and determinants. Heart. 2009; 95:728-732.

19. Allam Ah, Thompson RC, Wann LS, Miyamoto MI. Computed Tomographic Assessment of Atherosclerosis in Ancient Egyptian Mummies. JAMA. 2009;302:2091-2094.

20. Morrow DA, Antman EM. Evaluation of high-sensitivity assays for cardiac troponin. Clin Chem. 2009;55:5-8.

21. Bertrand ME, Simoons ML, Fox KA, et al. Task Force on the Management of Acute Coronary Syndromes of the European Society of Cardiology. Management of acute coronary syndromes in patients presenting without persistent ST-segment elevation. Eur Heart J. 2002;23:1809-1840.

22. Cannon R. Microvascular angina and the continuing dilemma of chest pain with normal coronary arteries $J$ Am Coll Cardiol. 2009;54: 877-885.

23. Asbury EA, Collins P. Cardiac Syndrome X. Int J Clin Pract. 2005; 59:1063-1069.

24. Mayer S, Hillis LD. Prinzmetal's vriant angina. Clin Cardiol. 1998; 21:243-246.

25. Vandergoten P, Benit E, Dendale P. Prinzmetal's variant angina: three case reports and a review of the literature. Acta Cardiol. 1999;54:71-76.

26. Sueda S, Kohno H, Fukuda H, et al. Limitations of medical therapy in patients with pure coronary spastic angina. Chest. 2003;123: 380-386.

27. Ong P, Athanasiadis A, Hill S, et al. Coronary artery spasm as a frequent cause of acute coronary syndrome: the CASPAR (Coronary Artery Spasm in Patients with Acute Coronary Syndrome) study. $J$ Am Coll Cardiol. 2008;52:523-527.

28. Eagle KA, Goodman SG, Avezum A, Budaj A, Sullivan CM, Lopez-Sendon J; GRACE Investigators. Practice variation and missed opportunities for reperfusion in ST-segment elevation myocardial infarction: findings from the Global Registry of Acute Coronary Events (GRACE). Lancet. 2002;359:373-377.

29. Hwang SY, Park EH, Shin ES, Jeong MH. Comparison of factors associated with atypical symptoms in younger and older patients with acute coronary syndromes. J Korean Med Sci. 2009;24: 789-794.

30. Kachintorn U. How do we define non-cardiac chest pain? J Gastroenterol Hepatol. 2005;20(Suppl):S2-S5.

31. Eslick GD, Coulshed DS, Talley NJ. Diagnosis and treatment of noncardiac chest pain. Nat Clin Pract Gastroenterol Hepatol. 2005;2: 463-472.

32. Sheps DS, Creed F, Clouse RE. Chest pain in patients with cardiac and noncardiac disease. Psychosom Med. 2004;66:861-867.

33. Cayley WE Jr. Diagnosing the cause of chest pain. Am Fam Physician. 2005;72:2012-2021.

34. Fass R, Dickman R. Non-cardiac chest pain: An update. Neurogastroenterol Motil. 2006;18:408-417.

35. Ringstrom E, Freedman J. Approach to undifferentiated chest pain in the emergency department: A review of recent medical literature and published practice guidelines. Mt Sinai Med. 2006;73: 499-505.

36. Hewson EG, Sinclair JW, Dalton CB, et al. Twenty-four hour esophageal $\mathrm{pH}$ monitoring: The most useful test for evaluating noncardiac chest pain. Am J Med. 1994;90:576-583.

37. Zahner MR, Li DP, Chen SR, Pan HL. Cardiac vanilloid receptor 1 -expressing afferent nerves and their role in the cardiogenic sympathetic reflex in rats. J Physiol (Lond). 2003;551:515-523.

38. Pan HL, Chen SR. Sensing tissue ischemia: another new function for capsaicin receptors? Circulation. 2004;110:1826-1831.

39. Ustinova EE, Bergren D, Schultz HD. Neuropeptide depletion impairs postischemic recovery of the isolated rat heart: role of substance P. Cardiovasc Res. 1995;30:55-63.

40. Bolli R. Cardioprotective function of inducible nitric oxide synthase and role of nitric oxide in myocardial ischemia and preconditioning: an overview of a decade of research. J Mol Cell Cardiol. 2001; $33: 1897-1918$ 
41. Bolli R, Abdel-Latif A. No pain, no gain: The useful function of Angina. Circulation. 2005;112:3541-3543.

42. Wang L, Wang DH. TRPV1 gene knockout impairs postischemic recovery in isolated perfused heart in mice. Circulation. 2005; 112:3617-3623.

43. Foreman RD, Qin CQ. Neuromodulation of cardiac pain and cerebral vasculature: Neural mechanisms. Cleveland Clin J Med. 2009;76:S75-S79.

44. Camici PG, Pagani M. Cardiac Nociception. Circulation. 2006;114: 2309-2312.

45. Yano K, MacLean CJ. The incidence and prognosis of unrecognized myocardial infarction in the honolulu, hawaii, heart program. Arch Intern Med. 1989;149(7):1528-1532.

46. de Torbal A, Boersma E, Kors JA, et al. Incidence of recognized and unrecognized myocardial infarction in men and women aged 55 and older: The Rotterdam Study. Eur Heart J. 2006;27:729-736.

47. Aronow WS, Silent MI. Prevalence and prognosis in older patients diagnosed by routine electrocardiograms. Geriatrics. 2003;58:24-26, 36-38,40.

48. Zellweger MJ, Hachamovitch R, Kang X, et al. Threshold, incidence, and predictors of prognostically high-risk silent ischemia in asymptomatic patients without prior diagnosis of coronary artery disease. J Nuclear Cardiol. 2009;16(2):193-200.

49. Deedwania P, Stone PH, Merz CNB, et al. Effects of intensive versus moderate lipid-lowering therapy on myocardial ischemia in older patients with coronary heart disease: Results of the Study Assessing Goals in the Elderly (SAGE). Circulation. 2007;115:700-707.

50. Parker JO, Chiong MA, West RO, et al. Sequential alterations in myocardial lactate metabolism, ST segments, and left ventricular function during angina induced by atrial pacing. Circulation. 1969;40:113-131.

51. Scirica BM, Morrow DA, Budaj A, et al. Ischemia detected on continuous electrocardiography after acute coronary syndrome: observations from the MERLIN-TIMI 36 (Metabolic Efficiency With Ranolazine for Less Ischemia in Non-ST-Elevation Acute Coronary SyndromeThrombolysis In Myocardial Infarction 36) Trial. J Am Coll Cardiol. 2009;53:1411-1421.

52. Norgaard BL, Andersen K, Dellborg M, et al. The TRIM Study Group. Admission risk assessment by cardiac Troponin T in unstable coronary artery disease: Additional prognostic information from continuous ST segment monitoring. J Am Coll Cardiol. 1999; 33:1519-1527.

53. Deedwania PC, Carbajal EV. Silent ischemia during daily life is an independent predictor of mortality in stable angina. Circulation. 1990;81:748-756.

54. Gotto JR AM. Statin therapy and the elderly: SAGE Advice? Circulation. 2007;115:681-683.

55. Erne P, Schoenenberger AW, Zuber M, et al. Effects of anti-ischaemic drug therapy in silent myocardial ischaemia type I: the Swiss Interventional Study on Silent Ischaemia type I (SWISSI I): a randomized, controlled pilot study. Eur Heart J. 2007;28:2110-2117.

56. Cohn PF. A new look at benefits of drug therapy in silent myocardial ischaemia. Eur Heart J. 2007;28:2053-2054.

57. Kwong RY, Chan AK, Brown KA, et al. Impact of unrecognized myocardial scar detected by cardiac magnetic resonance imaging on event-free survival in patients presenting with signs or symptoms of coronary artery disease. Circulation. 2006;113:2733-2743.

58. Dweck M, Campbell IW, Miller D, Francis CM. Clinical aspects of silent myocardial ischaemia: with particular reference to diabetes mellitus. Brit J Diab Vasc Disease. 2009;9:110-116.

59. Gibbons RJ, Abrams J, Chatterjee K, et al. ACC/AHA 2002 guideline update for the management of patients with chronic stable angina summary article: a report of the American College of Cardiology/ American Heart Association Task Force on practice guidelines (Committee on the Management of Patients With Chronic Stable Angina). J Am Coll Cardiol. 2003;41:159-168.
60. The Criteria Committee of the New York Heart Association. Nomenclature and Criteria for Diagnosis of Diseases of the Heart and Great Vessels. 9th ed. Boston: Little, Brown \& Co; 1994:253-256.

61. Campeau L. The Canadian Cardiovascular Society grading of angina pectoris revisited 30 years later. Can J Cardiol. 2002;18:371-379.

62. Hackett TP, Cassem NH. Psychological aspects of rehabilitation following myocardial infarction. In: Wenger NK, Hellerstein HK. Rehabilitation of the Coronary Patient. John Wiley and Sons. 1978;243-253.

63. Shub C, Click RL, Goon MD. Myocardial ischemia clinical syndromes; B: Angina pectoris and coronary heart disease. In: Giuliani ER, Gersh BJ, et al. Mayo Clinic Practice of Cardiology. 3rd ed. Mosby. 1996;1160-1190.

64. Kones R: Metabolism of the acutely ischemic and hypoxic heart. Crit Care Med. 1973;1:321-330.

65. Kones R. Molecular and ionic basic of altered myocardial contractility. Res Commun Chem Pathol Pharmacol. 1973;5:1-84.

66. Kones R. Cardiogenic Shock. Armonk NY: Futura-Blackwell Publishing; 1974.

67. Feigl EO. Coronary physiology. Physiol Rev. 1983;63:1-205.

68. Kones R. Pathogenesis of cardiogenic Shock II. N Y State J Med. 1973;73:1662-1670.

69. Duncker DJ, Bache RJ. Regulation of coronary blood flow during exercise. Physiol Rev. 2008;88:1009-1086.

70. Westerhof N, Boer C, Lamberts RR, Sipkema P. Cross-talk between cardiac muscle and coronary vasculature. Physiol Rev. 2006;86: 1263-1308.

71. Collins P. Coronary Flow Reserve. Br Heart J. 1993;69:279-281.

72. Hoole P, Heck PM, White PA, et al. Ischemic preconditioning stimulus does not reduce microvascular resistance or improve myocardial blood flow in patients undergoing elective percutaneous coronary intervention. Angiology. 2009;60(4):403-411.

73. Klocke FJ, Baird MG, Lorell BH, et al. ACC/AHA/ASNC guidelines for the clinical use of cardiac radionuclide imaging: executive summary - a report of the American College of Cardiology/ American Heart Association Task Force on Practice Guidelines (ACC/AHA/ASNC Committee to Revise the 1995 Guidelines for the Clinical Use of Cardiac Radionuclide Imaging). Circulation. 2003;108:1404-1418.

74. Camici PG, Rimoldi OE. The clinical value of myocardial blood flow measurement. J Nucl Med. 2009;50:1076-1087.

75. Libby P, Theroux P. Pathophysiology of coronary artery disease. Circulation. 2005;111:3481-3488.

76. Pfeffer M, Braunwald E. Ventricular remodeling after myocardial infarction: experimental observations and clinical implications. Circulation. 1990;81:1161-1172.

77. Dollery CM, Libby P. Atherosclerosis and proteinase activation. Cardiovasc Res. 2006;69:625-635.

78. Croce K, Libby P. Intertwining of thrombosis and inflammation in atherosclerosis. Curr Opin Hematol. 2007;14:55-61.

79. Kramer M, Rittersma S, de Winter RJ, et al. Relationship of thrombus healing to underlying plaque morphology in sudden coronary death. J Am Coll Cardiol. 2010;55:122-132.

80. Levin RI. Plaque vulnerability pathologic form and patient fate. $J A m$ Coll Cardiol. 2010;55:133-134.

81. Kubo T, Imanishi T, Kashiwagi M, et al. Multiple coronary lesion instability in patients with acute myocardial infarction as determined by optical coherence tomography. Am J Cardiol. 2010;105:318-322.

82. Kones R. The Jupiter Study, CRP Screening, and aggressive statin therapy - implications for the primary prevention of cardiovascular disease. Ther Adv Cardiovasc Dis. 2009;3:309-315.

83. Fox K, Garcia MA, Ardissino D, et al. Task Force on the Management of Stable Angina pectoris of the European Society of Cardiology; ESC Committee for Practice Guidelines (CPG). Guidelines on the management of stable angina pectoris: executive summary: the Task Force on the Management of Stable Angina Pectoris of the European Society of Cardiology. Eur Heart J. 2006;27:1341-1381. 
84. AHA Guidelines for Cardiopulmonary Resuscitation and Emergency Cardiovascular Care, Part 8: Stabilization of the Patient With Acute Coronary Syndromes. Circulation. 2005;112 (Suppl 4): I239-I290.

85. Goldstein JA, Gallagher MJ, O’Neill WW, Ross MA, O’Neil BJ, Raff GL. A Randomized Controlled Trial of Multi-Slice Coronary Computed Tomography for Evaluation of Acute Chest Pain. J Am Coll Cardiol. 2007;49:863-871.

86. Hoffmann U, Bamberg F, Chae CU, et al. Coronary Computed Tomography Angiography for Early Triage of Patients With Acute Chest Pain: The ROMICAT (Rule Out Myocardial Infarction using Computer Assisted Tomography) Trial. J Am Coll. Cardiol. 2009;53:1642-1650.

87. Jaffe AS, Apple FS. High-Sensitivity Cardiac Troponin: Hype, Help, and Reality. Clin Chem. 2010;56:342-344.

88. Giannitsis E, Becker M, Kurz K, Hess G, Zdunek D, Katus HA. High-Sensitivity Cardiac Troponin T for Early Prediction of Evolving Non-ST-Segment Elevation Myocardial Infarction in Patients with Suspected Acute Coronary Syndrome and Negative Troponin Results on Admission. Clin Chem. 2010;56:642-650.

89. Keller T, Zeller T, Peetz D, Tzikas S, et al. Sensitive troponin I assay in early diagnosis of acute myocardial infarction. $N$ Engl J Med. 2009;361:868-877.

90. Reichlin T, Hochholzer W, Bassetti S, et al. Early diagnosis of myocardial infarction with sensitive cardiac troponin assays. $N$ Engl J Med. 2009;361:858-867.

91. Morrow DA. Clinical application of sensitive troponin assays. $N$ Engl J Med. 2009;361:913-915.

92. deFilippi CR, Tocchi M, Parmar RJ, et al. Cardiac troponin T in chest pain unit patients without ischemic electrocardiographic changes: angiographic correlates and long-term clinical outcomes. J Am Coll Cardiol. 2000;35:1827-1834.

93. Sánchez M. Predictors and outcomes of frequent chest pain unit users. Am J Emerg Med. 2009;27:660-667.

94. Oluboyede Y, Goodacre S, Wailoo A, for the ESCAPE Research Team. Cost effectiveness of chest pain unit care in the NHS. BMC Health Services Research. 2008;8:174.

95. Hill J, Timmis A. ABC of electrocardiography: Exercise tolerance testing. BMJ. 2002;324:1084-1087.

96. Gibbons RJ, Balady GJ, Beasley JW, et al. ACC/AHA Guidelines for Exercise Testing. A report of the American College of Cardiology/American Heart Association Task Force on Practice Guidelines (Committee on Exercise Testing). J Am Coll Cardiol. 1997;30:260-311.

97. Morise AP, Diamond GA. Comparison of the sensitivity and specificity of exercise electrocardiography in biased and unbiased populations of men and women. Am Heart J. 1995;130:741-747.

98. Mieres JH, Shaw LJ, Hendel RC, et al. American Society of Nuclear Cardiology consensus statement: task force on women and coronary artery disease - the role of myocardial perfusion imaging in the clinical evaluation of coronary artery disease in women [correction]. $\mathrm{J} \mathrm{Nucl}$ Cardiol. 2003;10:95-101.

99. Shaw LJ, Hachamovitch R, Iskandrian AE. Treadmill test scores: Attributes and Limitations. J Nucl Cardiol. 1997;4:74-75.

100. Chaitman BR. The changing role of the exercise electrocardiogram as a diagnostic and prognostic test for chronic ischemic heart disease. J Am Coll Cardiol. 1986;8:1195-1210.

101. Mark DB, Shaw L, Harrell FE Jr, et al. Prognostic value of a treadmill exercise score in outpatients with suspected coronary artery disease. N Eng J Med. 1991;325:849-853.

102. Gibbons RJ, Balady GJ, Bricker JT, et al. Committee Members Task Force Members. ACC/AHA 2002 Guideline Update for Exercise Testing: Summary Article: A Report of the American College of Cardiology/American Heart Association Task Force on Practice Guidelines (Committee to Update the 1997 Exercise Testing Guidelines) Circulation. 2002;106:1883-1892.
103. Mieres JH, Shaw LJ, Arai A, et al. Role of Noninvasive Testing in the Clinical Evaluation of Women With Suspected Coronary Artery Disease: Consensus Statement From the Cardiac Imaging Committee, Council on Clinical Cardiology, and the Cardiovascular Imaging and Intervention Committee, Council on Cardiovascular Radiology and Intervention, American Heart Association. Circulation. 2005;111:682-696

104. Jacobs AK. Coronary Intervention in 2009: Are Women No Different Than Men? Circ Cardiovasc Interv. 2009;2:69-78.

105. Udelson JE, Beshansky JR, Ballin DS, et al. Myocardial perfusion imaging for evaluation and triage of patients with suspected acute cardiac ischemia: A randomized controlled trial. JAMA. 2002;288:2693-2700.

106. Douglas PS, Taylor A, Bild D, et al. Outcomes Research in Cardiovascular Imaging: Report of a Workshop Sponsored by the National Heart, Lung, and Blood Institute. J Am Coll Cardiol Img. 2009;2:897-907.

107. Pouleur AC, Le Polain de Waroux JB, Kefer J, Pasquet A, Vanoverschelde JL, Gerber BL. Direct comparison of whole-heart, navigatorgated magnetic resonance coronary angiography and 40/64-slice multi-detector row computed tomography to detect coronary artery stenosis in patients scheduled for conventional coronary angiography. Circ Cardiovasc Imaging. 2008;1:114-121.

108. Lee J, Niederer S, Nordsletten D, et al. Coupling contraction, excitation, ventricular and coronary blood flow across scale and physics in the heart. Phil Trans R Soc A. 2009;367:2311-2331.

109. Pennell DJ. Cardiovascular Magnetic Resonance. Circulation 2010;121;692-705.

110. Kim HW, Farzaneh-Far A, Kim RJ. Cardiovascular Magnetic Resonance in Patients With Myocardial Infarction: Current and Emerging Applications. J Am Coll Cardiol. 2010;55:1-16.

111. de Feyter PJ, van Geuns RJ. Noninvasive Coronary Imaging: The Contest between Magnetic Resonance and Computed Tomographic Coronary Angiography. Circ Cardiovasc Imaging. 2008;1:89-91.

112. Hendel RC, Berman DS, Di Carli MF, et al. ACCF/ASNC/ACR/AHA ASE/SCCT/SCMR/SNM 2009 appropriate use criteria for cardiac radionuclide imaging: a report of the American College of Cardiology Foundation Appropriate Use Criteria Task Force, the American Society of Nuclear Cardiology, the American College of Radiology, the American Heart Association, the American Society of Echocardiography, the Society of Cardiovascular Computed Tomography, the Society for Cardiovascular Magnetic Resonance, and the Society of Nuclear Medicine. J Am Coll Cardiol. 2009;53:2201-2229.

113. Emond M, Mock MB, Davis KB, et al. Long-term survival of medical treated patients in the Coronary Artery Surgery Study (CASS) Registry. Circulation. 1994;90:2645

114. Mensah GA, Mokdad AH, Ford ES, Greenlund KJ, Croft JB. State of disparities in cardiovascular health in the United States. Circulation. 2005;111:1233-1241.

115. Mosca L, Grundy SM, Judelson D, et al. American Heart Association/American College of Cardiology AHA/ACC scientific statement consensus panel statement. Guide to preventive cardiology for women. Circulation. 1999;99:2480-2484.

116. Shaw LJ, Merz CN, Pepine CJ, et al; for the WISE investigators. Insights from the NHLBI-sponsored Women's Ischemia Syndrome Evaluation (WISE) study. J Am Coll Cardiol. 2006;47(Suppl):S4-S20.

117. Hemingway H, Langenberg C, Damant J, et al. Prevalence of angina in women versus men: a systematic review and metaanalysis of international variations across 31 countries. Circulation. 2008;117:1526-1536.

118. Chou AF, Wong L, Weisman CS, et al. Gender disparities in cardiovascular disease care among commercial and medicare managed care plans. Womens Health Issues. 2007;17:139-149.

119. Lansky AJ, Hochman JS, Ward PA, et al; American College of Cardiology Foundation; American Heart Association. Percutaneous coronary intervention and adjunctive pharmacotherapy in women: a statement for healthcare professionals from the American Heart Association. Circulation. 2005;111:940-953. 
120. Milner KA, Vaccarino V, Arnold AL, Funk M, Goldberg RJ. Gender and age differences in chief complaints of acute myocardial infarction (Worcester Heart Attack Study). Am J Cardiol. 2004; 93:606-608

121. Arslanian-Engoren C, Patel A, Fang J, et al. Symptoms of men and women presenting with acute coronary syndromes. Am J Cardiol. 2006; 98:1177-1181.

122. Bosner S, Hassenritter J, Hani MA, et al. Gender differences in presentation and diagnosis of chest pain in primary care. BMC Family Practice. 2009;10:79.

123. DeVon HA, Ryan CJ, Ochs AL, Shapiro M. Symptoms across the continuum of acute coronary syndromes: differences between women and men. Am J Crit Care. 2008;17:14-25.

124. Bessant R, Hingorani A, Patel L, MacGregor A, Isenberg DA, Rahman A. Risk of coronary heart disease and stroke in a large British cohort of patients with systemic lupus erythematosus. Rheumatology (Oxford). 2004;43:924-929.

125. Von Mering GO, Arant CB, Wessel TR, et al. National Heart, Lung and Blood Institute. Abnormal coronary vasomotion as a prognostic indicator of cardiovascular events in women: results from the National Heart, Lung, and Blood Institute-Sponsored Women's Ischemia Syndrome Evaluation (WISE). Circulation. 2004;109: 722-725.

126. Reis SE, Holubkov R, Conrad Smith AJ, et al. Coronary microvascular dysfunction is highly prevalent in women with chest pain in the absence of coronary artery disease: results from the NHLBI WISE study. Am Heart J. 2001;141:735-741.

127. Sun $\mathrm{H}$, Mohr M, Shimokawa $\mathrm{H}$, et al. Coronary microvascular spasm causes myocardial ischemia in patients with vasospastic angina. $J \mathrm{Am}$ Coll Cardiol. 2002;39:847-851.

128. Hibino H, Kurachi Y. A new insight into the pathogenesis of coronary vasospasm. Circ Res. 2006;98:579-581.

129. Kakkar R, Ye B, Stoller DA, et al. Spontaneous coronary vasospasm in KATP mutant mice arises from a smooth muscle-extrinsic process. Circ Res. 2006;98:682-689.

130. Han SH, Bae JH, Holmes DR, et al. Sex differences in atheroma burden and endothelial function in patients with early coronary atherosclerosis. Eur Heart J. 2008;29:1359-1369.

131. Colacurci N, Manzella D, Fornaro F, Carbonella M, Paolisso G. Endothelial function and menopause: effects of raloxifene administration J Clin Endocrinol Metab. 2003;88:2135-2140.

132. Rossi R, Nuzzo A, Origliani G, Modena MG. Prognostic role of flowmediated dilation and cardiac risk factors in post-menopausal women. J Am Coll Cardiol. 2008;51:997-1002.

133. Becker DM, Segal J, Vaidya D, et al. Sex differences in platelet reactivity and response to low-dose aspirin therapy. JAMA. 2006;295:1420-1427.

134. Ridker PM, Cook NR, Lee IM, et al. A randomized trial of low-dose aspirin in the primary prevention of cardiovascular disease in women. N Engl J Med. 2005;352:1293-1304.

135. Rosamond W, Flegal K, Furie K, et al. for the Writing Group Members. Heart disease and stroke statistics - 2008 update: a report from the American Heart Association Statistics Committee and Stroke Statistics Subcommittee. Circulation. 2008;117:e25-e146.

136. Ford ES, Capewell S. Coronary heart disease mortality among young adults in the U.S. from 1980 through 2002: concealed leveling of mortality rates. J Am Coll Cardiol. 2007;50:2128-2132.

137. Centers for Disease Control and Prevention Racial/Ethnic Disparities in Prevalence, Treatment, and Control of Hypertension - United States, 1999-2002. http://www.cdc.gov/mmwr/preview/mmwrhtml/ mm5401a3.htm. Accessed Aug 25, 2008.

138. Ni H, Coady S, Rosamond W, et al. Trends from 1987 to 2004 in sudden death due to coronary heart disease: the Atherosclerosis Risk in Communities (ARIC) study. Am Heart J. 2009;157:46-52.
139. Wong TY, Klein R, Sharrett AR, et al. Retinal arteriolar narrowing and risk of coronary heart disease in men and women. JAMA. 2002; 287:1153-1159.

140. Shaw LJ, Shaw RE, Bairey Merz CN, et al. Impact of ethnicity and gender differences on angiographic coronary artery disease prevalence and in-hospital mortality in the American College of CardiologyNational Cardiovascular Data Registry (ACC-NCDR). Circulation. 2008;117:1787-1801.

141. Bairey Merz CN, Shaw LJ, Reis SE. Ischemic heart disease in women: insights from the NHLBI-sponsored Women's Ischemia Syndrome Evaluation (WISE) Study. Part II: Gender differences in presentation, diagnosis, and outcome with regard to sex-based pathophysiology of atherosclerosis, macro- and micro-vascular CAD. J Am Coll Cardiol. 2006;47(Suppl):21s-29s.

142. Burke AP, Farb A, Malcolm GT, Liang Y, Smialek J, Virmani R. Effects of risk factors on the mechanism of acute thrombosis and sudden coronary death in women. Circulation. 1998;97: 2110-2116.

143. Burke AP, Virmani R, Galis Z, Haudenschild CC, Muller JE. 34th Bethesda Conference: Task force $\# 2$ - what is the pathologic basis for new atherosclerosis imaging techniques? $\mathrm{J} \mathrm{Am} \mathrm{Coll} \mathrm{Cardiol.}$ 2003;41:1874-1886.

144. Akahoshi M, Soda M, Nakashima E, et al. Effects of menopause on trends of serum cholesterol, blood pressure, and body mass index. Circulation. 1996;94:61-66.

145. Derby CA, Crawford SL, Pasternak RC, Sowers M, Sternfeld B, Matthews KA. Lipid changes during the menopause transition in relation to age and weight: The Study of Women's Health Across the Nation. Am J Epidemiol. 2009;169(11):1352-1361.

146. McTigue K, Larson JC, Valoski A, et al. Mortality and cardiac and vascular outcomes in extremely obese women. JAMA. 2006;296:79-86.

147. Janssen I, Powell LH, Crawford S, Lasley B, Sutton-Tyrrell K. Menopause and the metabolic syndrome: The Study of Women's Health Across the Nation. Arch Intern Med. 2008;168(14): $1568-1575$.

148. Ramos RG, Olden K. The prevalence of metabolic syndrome among US women of childbearing age. Am J Public Health. 2008;98:1122-1127.

149. Hokanson JE, Austin MA. Plasma triglyceride level is a risk factor for cardiovascular disease independent of high-density lipoprotein level: a meta-analysis of population-based prospective studies. J Cardiovasc Risk. 1996;3:213-219.

150. Barrett-Connor EL, Cohn BA, Wingard DL, Edelstein SL. Why is diabetes mellitus a stronger risk factor for fatal ischemic heart disease in women than in men? The Rancho Bernardo Study. JAMA. 1991;265:627-631.

151. Gregg EW, Gu Q, Cheng YJ, Narayan KM, Cowie CC. Mortality trends in men and women with diabetes. Ann Intern Med. 2007; 147:149-155.

152. Wong ND, Pio J, Valencia R, Thakal G. Distribution of C-reactive protein and its relation to risk factors and coronary heart disease risk estimation in the National Health and Nutrition Examination Survey (NHANES) III. Prev Cardiol. 2001;4:109-114.

153. Ridker PM, Buring JE, Cook NR, Rifai N. C-reactive protein, the metabolic syndrome, and risk of incident cardiovascular events: an 8- year follow-up of 14,719 initially healthy American women. Circulation. 2003;107:391-397.

154. Cook NR, Buring JE, Ridker PM. The effect of including C-reactive protein in cardiovascular risk prediction models for women. Ann Intern Med. 2006;145:21-29.

155. Pasternak RC, Abrams J, Greenland P, et al. 34th Bethesda Conference: task force $\# 1$ - identification of coronary heart disease risk: is there a detection gap? J Am Coll Cardiol. 2003;41:1863-1874. 
156. Lakoski SG, Greenland P, Wong ND, Schreiner PJ, et al. Coronary artery calcium scores and risk for cardiovascular events in women classified as "low risk" based on Framingham risk score: the Multi-Ethnic Study of Atherosclerosis (MESA). Arch Intern Med. 2007;167:2437-2442.

157. Ridker PM, Buring JE, Rifai N, Cook NR. Development and validation of improved algorithms for the assessment of global cardiovascular risk in women: the Reynolds Risk Score. JAMA. 2007;297:611-619.

158. O'Keefe-McCarthy S. Women's experiences of cardiac pain: a review of the literature. Can J Cardiovasc Nurs. 2008;18:18-25.

159. Douglas PS, Ginsburg GS. The evaluation of chest pain in women. N Engl J Med. 1996;334:1311-1315.

160. Ting HH, Bradley EH, Wang Y, et al. Factors associated with longer time from symptom onset to hospital presentation for patients with ST-elevation myocardial infarction. Arch Intern Med. 2008;168:959-968.

161. Concannon TW, Griffith JL, Kent DM, et al. Elapsed Time in emergency medical services for patients with cardiac complaints: are some patients at greater risk for delay? Circ Cardiovasc Qual Outcomes. 2009;2:9-15.

162. Ornato JP. Gender Delay in Emergency Medical Services: Does it Really Exist? Circ Cardiovasc Qual Outcomes. 2009;2:4-5.

163. Johnson BD, Kelsey SF, Bairey Merz CN. Clinical risk assessment in women: chest discomfort. Report from the WISE study. Shaw LJ, Redberg RF, editors. CAD in Women: Evidence-Based Diagnosis and Treatment. Totowa, NJ: Humana Press;2003;129-142.

164. Johnson BD, Bairey Merz CN, Kelsey SF, et al. Persistent chest pain predicts cardiovascular events in women with and without obstructive coronary artery disease: results from the NHLBI-sponsored WISE study. Eur Heart J. 2006;27:1408-1415.

165. Shaw LJ, Bairey Merz CN, Pepine CJ, et al. for the Women's Ischemia Syndrome Evaluation (WISE) Investigators. The Economic Burden of Angina in Women With Suspected Ischemic Heart Disease: Results From the National Institute of Health - National Heart, Lung, and Blood Institute - Sponsored Women's Ischemia Syndrome Evaluation (WISE). Circulation. 2006;114:894-904.

166. Shaw LJ, Heller GV, Travin MI, et al. Cost analysis of diagnostic testing for coronary artery disease in women with stable chest pain. J Nucl Cardiol. 1999;6:559-569.

167. Olson MB, Kelsey SF, Matthews K, et al. Symptoms, myocardial ischaemia and quality of life in women: results from the NHLBIsponsored WISE Study. Eur Heart J. 2003;24:1506-1514.

168. KwokYS, Kim C, Grady D, et al. Meta-analysis of exercise testing to detect coronary artery disease in women. Am J Cardiol. 1999;83:660-666.

169. Gulati M, Arnsdorf MF, Shaw LJ, et al. Prognostic value of the duke treadmill score in asymptomatic women. Am J Cardiol. 2005; 96:369-375.

170. Gulati M, Pandey DK, Arnsdorf MF, et al. Exercise capacity and the risk of death in women. Circulation. 2003;108:1554-1559.

171. Kavanagh T, Mertens DJ, Hamm LF, et al. Peak oxygen intake and cardiac mortality in women referred for cardiac rehabilitation. J Am Coll Cardiol. 2003;42:2139-2143.

172. Shaw LJ, Iskandrian AE. Prognostic value of stress gated SPECT in patients with known or suspected coronary artery disease. $\mathrm{J} \mathrm{Nucl}$ Cardiol. 2004;11:171-185.

173. Shaw LJ, Vasey C, Sawada S, Rimmerman C, Marwick TH. Impact of gender on risk stratification by exercise and dobutamine stress echocardiography: long-term mortality in 4,234 women and 6,898 men. Eur Heart J. 2005;26:447-456.

174. Sicari R, Pasanisi E, Venneri L, Landi P, Cortigiani L, Picano E. Echo Persantine International Cooperative (EPIC) Study Group. Echo Dobutamine International Cooperative (EDIC) Study Group. Stress echo results predict mortality: a large-scale multicenter prospective international study. J Am Coll Cardiol. 2003;41:589-595.
175. Sharaf BL, Pepine CJ, Kerensky RA, et al. Detailed angiographic analysis of women with suspected ischemic chest pain (pilot phase data from the NHLBI-sponsored Women's Ischemia Syndrome Evaluation [WISE] Study Angiographic Core Laboratory). Am J Cardiol. 2001;87:937-941.

176. Bugiardini R, Bairey Merz CN. Angina with "normal” coronary arteries: a changing philosophy. JAMA. 2005;293:477-484.

177. Anderson RD, Pepine CJ. Gender differences in the treatment for acute myocardial infarction: bias or biology? Circulation. 2007; 115:823-826.

178. Cook NL, Ayanian JZ, Orav EJ, Hicks LS. Differences in specialist consultations for cardiovascular disease by race, ethnicity, gender, insurance status, and site of primary care. Circulation. 2009;119:2463-2470.

179. Lansky AJ. Outcomes of percutaneous and surgical revascularization in women. Prog Cardiovasc Dis. 2004;46:305-319.

180. Modena MG, Bonetti L, Coppi F, et al. Prognostic role of reversible endothelial dysfunction in hypertensive postmenopausal women. $\mathrm{JAm}$ Coll Cardiol. 2002;40:505-510.

181. Ky B, Kirwan BA, de Brouwer S, et al. Gender differences in cardiac remodeling and clinical outcomes in chronic stable angina pectoris (from the ACTION Trial). Am J Cardiol. 2010;105:943-947.

182. Chang WC, Kaul P, Westerhout CM, et al. Impact of sex on long-term mortality from acute myocardial infarction vs unstable angina. Arch Intern Med. 2003;163:2476-2484.

183. Schenck-Gustafson K. How do gender differences affect cardiovascular risk factors? Dialogues in Cardiovasc Med. 2008;13: 103-110.

184. Homvang L, Mickley H. Gender differences following percutaneous coronary intervention. Ther Adv Cardiovasc Dis. 2008; 2:109-113.

185. Setoguchi S, Solomon DH, Levin R, Winkelmayer WC. Gender differences in the management and prognosis of myocardial infarction among patients $\geq 65$ years of age. Am J Cardiol. 2008;101: 1531-1536.

186. Yarnoz MJ, Curtis AB. More reasons why men and women are not the same (gender differences in electrophysiology and arrhythmias). Am J Cardiol. 2008;101:1291-1296.

187. Yarnoz MJ, Curtis AB. Sex-based differences in cardiac resynchronization therapy and implantable cardioverter-defibrillator therapies: effectiveness and use. Cardiol Rev. 2006;14:292-298.

188. Humphries KH, Pu A, Gao M, Carere RG, Pilote M. Angina with "normal" coronary arteries: sex differences in outcomes. Am Heart J. 2008;155:375-381.

189. Blomkalns AL, Chen AY, Hochman JS, et al. Gender disparities in diagnosis \& treatment of non-ST-segment elevation acute coronary syndromes. J Am Coll Cardiol. 2005;45:832-837.

190. Hvelplund A, Galatius S, Madsen M, et al. Women with acute coronary syndrome are less invasively examined and subsequently less treated than men. Eur Heart J. 2010;31:684-690.

191. Mosca L, Mochari-Greenberger H, Dolor RJ, Kristin Newby L, Karen J. Robb. Twelve-year follow-up of American women's awareness of cardiovascular disease risk and barriers to heart health. Circ Cardiovasc Qual Outcomes. 2010;3:120-127.

192. Gan SC, Beaver SK, Houck PM, MacLehose RF, Lawson HW, Chan L. Treatment of acute myocardial infarction and 30-day mortality among women and men. N Engl J Med. 2000;343:8-15.

193. Boden WE, O'Rourke RA, Teo KK, et al. Optimal medical therapy with or without PCI for stable coronary disease. $N$ Engl J Med. 2007;356:1503-1516.

194. O’Donoghue M, Boden WE, Braunwald E, et al. Early invasive vs conservative treatment strategies in women and men with unstable angina and non-ST-segment elevation myocardial infarction. JAMA. 2008;300:71-80. 
195. Anderson JL, Adams CD, Antman EM, et al. ACC/AHA 2007 guidelines for the management of patients with unstable angina/non-ST elevation myocardial infarction: a report of the American College of Cardiology/American Heart Association Task Force on Practice Guidelines (Writing Committee to Revise the 2002 Guidelines for the Management of Patients With Unstable Angina/Non-ST-Elevation Myocardial Infarction). J Am Coll Cardiol. 2007;50:e1-e157.

196. Steg P, Himberg D. Unmet medical needs and therapeutic opportunities in stable angina. Eur Heart J. 2005;7:H7-H15.

197. Mannheimer C, Camici P, Chester MR, et al. The problem of chronic refractory angina; report from the ESC Joint Study Group on the Treatment of Refractory Angina. Eur Heart J. 2002;23:355-370.
198. Fraker TD Jr, Fihn SD, Writing on behalf of the 2002 Chronic Stable Angina Writing Committee 2007 Chronic Angina Focused Update of the ACC/AHA 2002 Guidelines for the Management of Patients With Chronic Stable Angina. A Report of the American College of Cardiology/American Heart Association Task Force on Practice Guidelines Writing Group to Develop the Focused Update of the 2002 Guidelines for the Management of Patients With Chronic Stable Angina. J Am Coll Cardiol. 2007;50:2264-2274.

199. Patel MR, Peterson ED, Dai D, et al. Low diagnostic yield of elective coronary angiography. $N$ Engl J Med. 2010;362:886-895.

\section{Publish your work in this journal}

Vascular Health and Risk Management is an international, peerreviewed journal of therapeutics and risk management, focusing on concise rapid reporting of clinical studies on the processes involved in the maintenance of vascular health; the monitoring, prevention and treatment of vascular disease and its sequelae; and the involvement of metabolic disorders, particularly diabetes. This journal is indexed on PubMed Central and MedLine. The manuscript management system is completely online and includes a very quick and fair peer-review system, which is all easy to use. Visit http://www.dovepress.com/ testimonials.php to read real quotes from published authors. 